\title{
Profile of Semiquinone Radicals, Phytohormones and Sugars in Pistacia vera L. cv. Kirmizi Development
}

\author{
Iwona Morkunas ${ }^{1, *(1)}$, Mehmet Zafer Doğu ${ }^{1}$, Agnieszka Woźniak ${ }^{1}\left(\right.$, Waldemar Bednarski $^{2}{ }^{\circledR}$, Jacek Kęsy ${ }^{3}$, \\ Jan Bocianowski ${ }^{4}{ }^{\circ}$, Şule Hilal Atar ${ }^{5}$, İpek Değirmenci Ürün ${ }^{5}$, Mateusz Labudda ${ }^{6}{ }^{\circ}$, Zofia Zydlik ${ }^{7} \mathbb{D}^{\circ}$, \\ Nesibe Ebru Kafkas ${ }^{5}$, Salih Kafkas ${ }^{5}$ and Philippe Jeandet ${ }^{8}$
}

1 Department of Plant Physiology, Faculty of Agronomy, Horticulture and Bioengineering, Poznań University of Life Sciences, Wołyńska 35, 60-637 Poznań, Poland; mzaferdogu@gmail.com (M.Z.D.); agnieszka.wozniak@up.poznan.pl or agnieszkam.wozniak@gmail.com (A.W.)

2 Institute of Molecular Physics, Polish Academy of Sciences, Smoluchowskiego 17, 60-179 Poznań, Poland; waldemar.bednarski@ifmpan.poznan.pl

3 Chair of Plant Physiology and Biotechnology, Nicolaus Copernicus University, Gagarina 9, 87-100 Torun, Poland; jacek.kesy@umk.pl

4 Department of Mathematical and Statistical Methods, Poznań University of Life Sciences, Wojska Polskiego 28, 60-637 Poznań, Poland; jan.bocianowski@up.poznan.pl

5 Department of Horticulture, University of Çukurova, 01330 Adana, Turkey; sulehilal35@gmail.com (Ş.H.A.); ipek-016@hotmail.com (İ.D.Ü.); ebruyasakafkas@gmail.com (N.E.K.); salihkafkas@gmail.com (S.K.)

6 Department of Biochemistry and Microbiology, Institute of Biology, Warsaw University of Life Sciences-SGGW, Nowoursynowska 159, 02-776 Warsaw, Poland; mateusz_labudda@sggw.edu.pl

7 Department of Dendrology and Nursery, Faculty of Agronomy, Horticulture and Bioengineering, Dabrowskiego 159, 60-594 Poznań, Poland; zofia.zydlik@up.poznan.pl

check for updates

Citation: Morkunas, I.; Doğu, M.Z.; Woźniak, A.; Bednarski, W.; Kęsy, J.; Bocianowski, J.; Atar, Ş.H.; Ürün, İ.D. Labudda, M.; Zydlik, Z.; et al. Profile of Semiquinone Radicals,

Phytohormones and Sugars in Pistacia vera L. cv. Kirmizi Development. Agronomy 2021, 11, 2115. https:// doi.org/10.3390/agronomy11112115

Academic Editor: José M. Palma

Received: 18 September 2021

Accepted: 19 October 2021

Published: 22 October 2021

Publisher's Note: MDPI stays neutral with regard to jurisdictional claims in published maps and institutional affiliations.

Copyright: (c) 2021 by the authors. Licensee MDPI, Basel, Switzerland. This article is an open access article distributed under the terms and conditions of the Creative Commons Attribution (CC BY) license (https:// creativecommons.org/licenses/by/ $4.0 /)$.
8 Research Unit "Induced Resistance and Plant Bioprotection", UPRES EA 4707, Department of Biology and Biochemistry, Faculty of Sciences, University of Reims, P.O. Box 1039, CEDEX 02, 51687 Reims, France; philippe.jeandet@univ-reims.fr

* Correspondence: iwona.morkunas@gmail.com or iwona.morkunas@up.poznan.pl; Tel.: +48-61-846-6040

Abstract: The main aim of this study was to investigate metabolic responses of fruits, leaves, and shoots of pistachio trees (Pistacia vera L. cv. Kirmizi) during their development. Electron paramagnetic resonance spectroscopy revealed significant increase in generation of semiquinone radicals in fruits and leaves of pistachio, while the flower cluster thinning application was conducted in relation to the control; especially at the second term of the plant material collection. Moreover, flower abscission caused an increase in the level of phytohormones such as indole-3-acetic acid and abscisic acid in fruits at the first term of fruits sampling. In turn, high-performance liquid chromatography analysis revealed differences both in the profile as well as the contents of soluble sugars detected in pistachio organs. The highest total sugar content was found in fruits of pistachio where the flower cluster thinning application was made early. Total sugar levels were higher also in leaves and shoots of the above-mentioned pistachio plants in relation to the control until the third sampling time. The importance of high levels of fructose in the fruits following the flower abscission was observed. Additionally, analyses of mineral elements in organs showed that copper and phosphorus contents in fruits were higher after the flower abscission in relation to the control. To conclude, our findings signal on contribution of semiquinone radicals, paramagnetic manganese ions, phytohormones, nutrients, and sugars in pistachio organs development on the background of the flower cluster thinning which was applied before fructification.

Keywords: electron paramagnetic resonance; pistachio; phytohormones; semiquinone radicals and paramagnetic centers; sugars

\section{Introduction}

Pistacia L. belongs to the family the Anacardiaceae (cashew family) [1] or order Sapindales [2]. It contains nine species and five subspecies [3]. Pistacia vera L. is believed to be 
the most ancestral species, whereas other species probably derived from it [4,5]. Recent research results of Karc1 et al. [6] provided evidence that simple sequence repeats markers can be used to the characterization and the phylogenetic analysis of Pistacia species and cultivars. Moreover, P. vera is a small, dioecious tree originating from Central Asia and the Middle East. The Anacardiaceae family contains also important other species such as mango, pepper tree and sumac [7]. The genus Pistachio is a xerophytic plant [8]. Interestingly, $P$. vera is also a glycophyte highly tolerant to salt because pistachios have the capacity to maintain relatively high photosynthetic rates during treatment with salts [9]. For these reasons, $P$. vera trees are remarkably interesting from the point of plant physiology and molecular biology. These trees require specific climatic conditions such as long, hot, dry summers and chilling in the winter, but do not tolerate ground that freezes. Growth requires a temperature above $38^{\circ} \mathrm{C}$ during the day and needs also low temperatures under $7^{\circ} \mathrm{C}$ during winter months for break bud dormancy [10]. It should also be mentioned that the environment of pistachio trees needs to be arid, because these trees do not do well in areas of high humidity. Besides, P. vera grows do well in all soil types but really thrives in deep, sandy loam. Additionally, there are reports of pistachio trees being resistant to cold and wind but also sensitive to very extreme climate conditions, such as extreme drought, prolonged frost and excessive dampness and high humidity [11]. Key abiotic factors such as high temperature [12] and water deficit were found to lead to increased shell spliting of pistachio nuts and allow pathogenic fungi to colonize the nuts and contaminate them with mycotoxins [13,14].

P. vera is one of the most popular tree nuts in the world, which grows in defined climatic conditions. Source literature points to two centers of diversity of cultivated pistachio. As reported by Kafkas [5] (2019), the first comprises the Mediterranean region of Europe, Northern Africa, and the Middle East countries. In turn, the second comprises the Eastern part of Zagros Mountains from Crimea to the Caspian Sea. Moreover, pistachio cultivation extended westward from its center of origin to Italy, Spain, and other Mediterranean regions of Southern Europe as well as to North Africa, the Middle East, China, more often the United States and Australia [15-17].

It should be noted that in the literature, there are few molecular and physiological studies regarding the development of pistachio trees, and they are fragmentary. Pistachio needs almost 10 years to start an early fruit period and 20 years to enter full production period [11]. In the case of these trees, alternate bearing phenomena occurs, which is characterized by the fact that in the bearing year the production is very good, while in the alternative year the production is limited [18]. Research by Gündeşli [19] revealed the important role of phytohormones on the alternate bearing of pistachio (P. vera $\mathrm{cv}$. Uzun) during different growth periods. The above author reported that gibberellin and abscisic acid (ABA) metabolites occurring in different organs play a key role in the control of pistachios during embryo development and flower bud abscission. Additionally, the importance of free polyamines in this phenomenon was also raised by Gündeşli [19]. Moreover, Okay et al. [20] reported that externally application of plant growth regulators to pistachio leads to regular yields, increases flower bud formation and prevents flower bud abscission. The above cited authors carefully analyzed seasonal changes of plant growth regulators to determine some physiological mechanisms like formation of flower buds, flower and fruit pouring and alternate bearing. Transcriptome analysis of $P$. vera L. cv. Bianca inflorescence buds in bearing and non-bearing shoots was carried out by Benny et al. [21], revealing differentially expressed genes, most of which being involved in sugar metabolism, plant hormone pathways, secondary metabolism and oxidative stress pathways.

It is extremely important and suitable to provide additional evidence regarding the mechanisms of pistachio tree fruiting versus time. The present work thus highlights for the first-time changes in the level of semiquinone radicals (stable radicals of organic origin) generation and paramagnetic center manganese ions $\left(\mathrm{Mn}^{2+}\right)$ in P. vera L. cv. Kirmizi organs at different developmental stages, where the flower cluster thinning was made before 
fructification. The electron paramagnetic resonance (EPR) method is one of the most sensitive techniques for detecting particles with unpaired electrons at concentrations as low as a fraction of ppm. Particles with unpaired electrons are rare in nature, but they include some transition metal ions (for the example $\mathrm{Mn}^{2+}$ ) and free radicals that have been studied in the present work. It should also be mentioned that EPR spectroscopy is a unique technique not only used to detect, identify, quantify free radicals, study molecular structures, geometry, and dynamics, but to observe labeled species in situ in biological system and understanding redox processes, reaction kinetics and catalysis.

Moreover, in the present study it was also important to understand the sequence of generation of these semiquinone radicals and the time-dependent aspect of these changes. It is well known that semiquinone and phenoxyl radicals are formed in plant cells as a result of the oxidation of the hydroxyl groups of phenols and polyphenols being their generation positively associated with other markers of oxidation, such as protein carbonyls and peroxides [22]. Our previous research has shown that these radicals are involved in the direct defense response of plants against biotic factors as well as being involved in strengthening the cell wall [23-29]. Additionally, we used EPR spectroscopy in order to highlight biochemical and physical properties of apple fruits in relation to differences in semiquinone radical concentration between organs of different apple tree varieties [30]. Moreover, one of the goals of the present work was also to examine the levels of signalling molecules such as phytohormones (i.e., indole-3-acetic acid, IAA; ABA and salicylic acid, SA), soluble sugars (sucrose, monosacharides and galactose) and nutrient elements in pistachio organs where the flower cluster thinning application was made before fructification. Changes in the level of signaling molecules, i.e., phytohormones and sugars that are involved in the plant signalling network affect the regulation of metabolism of pistachio trees. As reported by Kozlowski [31] in perennial woody plants, most carbohydrates are produced in leaves but some are also synthesized in buds, twigs, stems, flowers and fruits. Internal competition for carbohydrates from sources to sink organs occurs, due to changes in rates of carbohydrate movement and reversals in direction of carbohydrate transport, as the relative sink strengths of various organs change. Previous studies of Morkunas et al. [32] have provided an extensive body of information on the contribution of carbohydrates to metabolic reactions of plant cells. In plants, sugars are essential components as respiratory substrates for the generation of energy and metabolic intermediates that are then used for the synthesis of macromolecules [33,34]. Sugars have also important hormone-like functions as physiological signals, which cause activation or repression of many plant genes, and this in turn leads to specific metabolic effects.

In the published literature, there are few reports on molecular and metabolomic changes occurring during the development of pistachio trees. Identifying these changes both at the molecular and metabolic levels and understanding the interrelationship between the studied parameters will afford new knowledge in the context of the development of this plant. In this study, we focused mainly on pistachio fruits, but additional analyses were also performed on leaves and shoots to obtain comprehensive information on the relationships between all these organs.

\section{Materials and Methods}

\subsection{Plant Material and Growth Conditions}

This study was conducted in 2018 in pistachio orchard (Figure 1) (geographical location: $36^{\circ} 58^{\prime} 35.6^{\prime \prime}$ northern latitude and $37^{\circ} 51^{\prime} 34.9^{\prime \prime}$ eastern longitude). It should be mentioned that 'Kirmizi' variety mainly grows in the high-altitude parts of the Gaziantep region and is preferred due to its early ripening (i.e., beginning of September) [35]. 


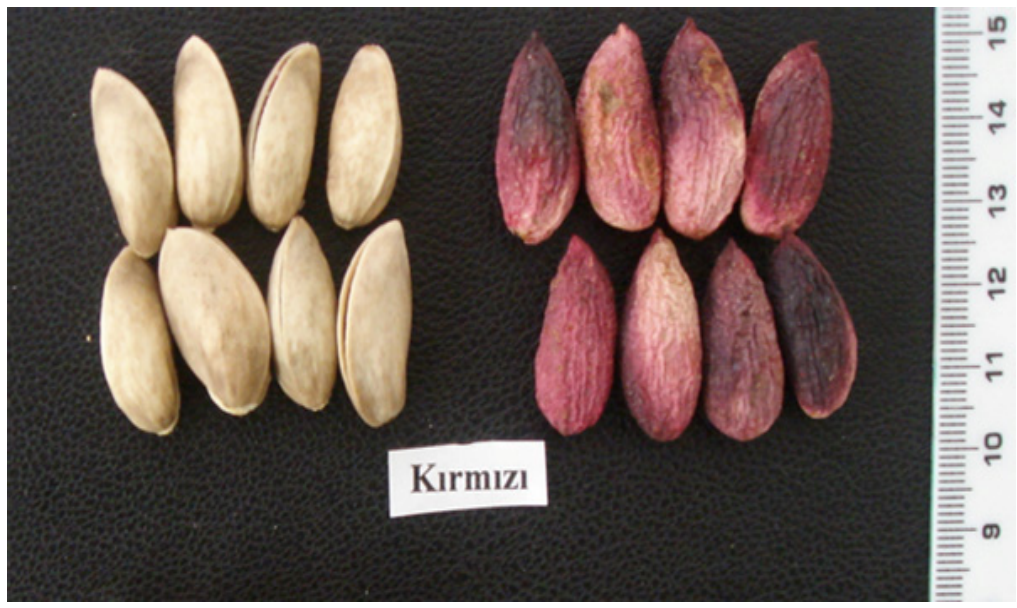

Figure 1. Nuts of P. vera L. cv. Kirimizi. (Own photography).

Samples of leaves, fruits (Figure 2) and shoots from 30-year-old 'Kirmizi' pistachio trees from Nizip region of Gaziantep, in 4 different periods from the beginning of May to the end of July from the thinning applied and non-applied branches, were used. Applied trees were thinned 1 month before first sampling date. Leaf, fruit (Figure 2) and shoot samples of this variety were brought from Gaziantep to Adana province in the cold chain condition and after harvesting immediately treated with liquid nitrogen and dried by freeze drying method (Ilshin FD5508 Bondiro Vacuum Freeze Dryer). All samples were homogenized with a coffee grinder and stored at $-80{ }^{\circ} \mathrm{C}$ until analyzed. The analyses were carried out in the Department of Plant Physiology, Faculty of Agronomy and Bioengineering of Poznan University of Life Sciences, Institute of Molecular Physics Polish Academy of Sciences in Poznań and Department of Plant Physiology and Biotechnology, Faculty of Biological and Veterinary Sciences of Nicolaus Copernicus University in Poland and in the Plant Nutrition Physiology and Chromatography Laboratories of the Cukurova University, Faculty of Agriculture, Department of Horticulture in Turkey.

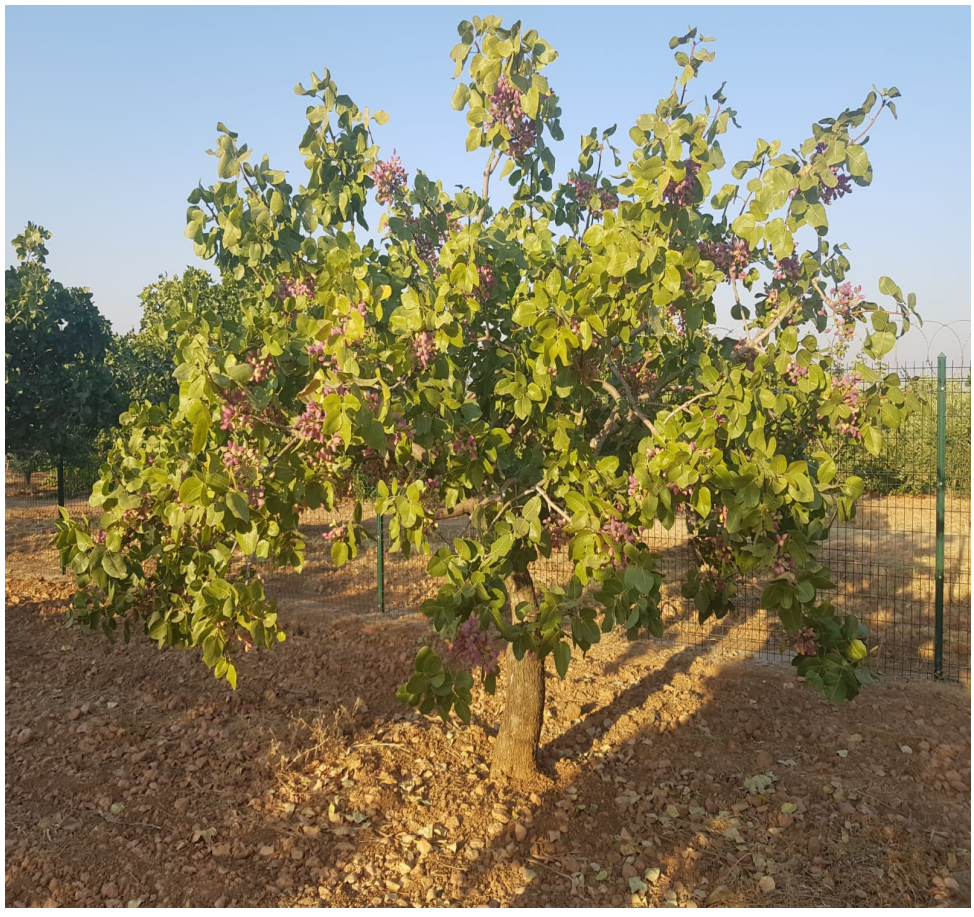

Figure 2. P. vera L. cv. Kirimizi. (Own photography). 


\subsection{Climatic Data of Research Area}

Climatic data for the research area were obtained from the General Directorate of Meteorology. Monthly and yearly average temperatures, maximum and minimum temperatures, the average hours of sunshine and mean rainfall values in the period of 2018-2019 years for Gaziantep province are given in Table 1.

Table 1. Average climatic values obtained for the 2018-2019 growing period in Gaziantep region in Turkey [36].

\begin{tabular}{|c|c|c|c|c|c|}
\hline Months & $\begin{array}{c}\text { Average } \\
\text { Temperature }\left({ }^{\circ} \mathrm{C}\right)\end{array}$ & $\begin{array}{l}\text { Average Maximum } \\
\text { Temperature }\left({ }^{\circ} \mathrm{C}\right)\end{array}$ & $\begin{array}{l}\text { Average Minimum } \\
\text { Temperature }\left({ }^{\circ} \mathrm{C}\right)\end{array}$ & $\begin{array}{l}\text { Average Hours of } \\
\text { Sunshine (Hours) }\end{array}$ & Total Rainfall (mm) \\
\hline January & 3.0 & 7.4 & -0.7 & 3.6 & 102.8 \\
\hline February & 4.4 & 9.3 & 0.1 & 4.4 & 83.4 \\
\hline March & 8.1 & 13.8 & 2.9 & 5.5 & 72.5 \\
\hline April & 13.3 & 19.6 & 7.2 & 7.0 & 52.7 \\
\hline May & 18.7 & 25.4 & 11.8 & 8.4 & 31.3 \\
\hline June & 24.2 & 31.1 & 17.0 & 10.3 & 8.5 \\
\hline July & 27.9 & 35.1 & 21.0 & 10.6 & 7.1 \\
\hline August & 27.7 & 35.2 & 20.9 & 10.0 & 5.2 \\
\hline September & 23.3 & 31.0 & 16.1 & 8.7 & 7.2 \\
\hline October & 16.6 & 24.1 & 9.9 & 6.9 & 37.3 \\
\hline November & 9.8 & 16.2 & 4.4 & 5.3 & 62.0 \\
\hline December & 4.9 & 9.6 & 1.0 & 3.5 & 98.5 \\
\hline Annual & 15.2 & 21.5 & 9.3 & 84.2 & 568.5 \\
\hline
\end{tabular}

\subsection{Electron Paramagnetic Resonance (EPR)}

Samples (leaves, shoots, and fruits) of P. vera were lyophilized and the lyophilized plant material was transferred to EPR-type quartz tubes of $4 \mathrm{~mm}$ in diameter. EPR measurements were performed at room temperature with a Bruker ELEXSYS X-band spectrometer (Bruker, Billerica, MA, USA). The EPR spectra were recorded as first derivatives of microwave absorption. A microwave power of $2 \mathrm{~mW}$ and a magnetic field modulation of about $2 \mathrm{G}$ was used for all the experiments to avoid signal saturation and deformation. EPR spectra of free radicals and $\mathrm{Mn}^{2+}$ were recorded in the magnetic field range of 1400-4200 G. To determine the number of paramagnetic centres in the samples, the spectra were doubleintegrated and compared with the intensity of the standard $\mathrm{Al}_{2} \mathrm{O}_{3}: \mathrm{Cr}^{3+}$ single crystal with a known spin concentration [24,29,37-41]. Before and after the first integration, some background corrections of the spectra were made to obtain a reliable absorption signal before the second integration. Free radicals gave signals with one g-values of $2.0045 \pm 0.0005$ while signals of $\mathrm{Mn}^{2+}$ were recorded with g-values of $2.00 \pm 0.01$ in leaves, shoots, and fruits.

\subsection{Detection of Phytohormones}

Samples (leaves, shoots, and fruits) of P. vera were homogenized in liquid nitrogen and extracted twice with $20 \mathrm{~mL} \mathrm{80 \%}(v / v)$ methanol containing $20 \mathrm{mg} / \mathrm{L}$ butylated hydroxytoluene. Subsequently deuterated internal standards of ABA, [ $\left.{ }^{2} \mathrm{H} 6\right] \mathrm{ABA}, \mathrm{IAA},\left[{ }^{2} \mathrm{H} 2\right] \mathrm{IAA}$ and SA, [ $\left.{ }^{2} \mathrm{H} 4\right] \mathrm{SA}$ (100 ng of each) were added as internal standards. The mixture was shaken overnight in a cold room. The extract was then centrifuged, and the supernatant was collected in evaporation flasks. The remaining pellet was resuspended two times in $10 \mathrm{~mL}$ of $80 \%(v / v)$ methanol, shaken for two hours and centrifuged again. The combined extracts were evaporated until all methanol was removed. The flasks were washed with additional $\mathrm{H}_{2} \mathrm{O}$ and the extract was collected in $50 \mathrm{~mL}$ Falcon tubes. The appropriate amount of $\mathrm{HCl}$ was added for acidification until $\mathrm{pH} 2$ was reached. This was checked with colored $\mathrm{pH}$ test strips. Then the extract was centrifuged, and the supernatant was collected into Erlenmeyer for solvent partition. The supernatant was partitioned three times against ethyl acetate. The organic phase was collected in evaporation flasks and dried under vacuum. The dry residue was then resolved in $5 \mathrm{~mL} 1 \mathrm{M}$ formic acid (FA) and loaded on a Discovery ${ }^{\circledR}$ DSC-18 SPE, 500 mg SPE cartridge (Supelco Inc., Bellefonte, PA, USA). These cartridges (columns) were preconditioned with $4 \mathrm{~mL}$ methanol and allowed to equilibrate with $4 \mathrm{~mL}$ of $1 \mathrm{M}$ FA. The columns were then washed with $4 \mathrm{~mL} 1 \mathrm{M}$ FA, 
$4 \mathrm{~mL}$ of $20 \%$ methanol in $1 \mathrm{M} \mathrm{FA}$ and finally phytohormones were eluted with $4 \mathrm{~mL}$ of $80 \%$ methanol in water. The eluate was evaporated to dryness, resolved in $200 \mu \mathrm{L}$ of $20 \%$ acetonitrile in water and applied to high-performance liquid chromatography (HPLC) for further sample purification. HPLC was done with a SUPELCOSIL ABZ+ PLUS column $(250 \times 4.5 \mathrm{~mm}, 5 \mu \mathrm{m}$ particle size, Supelco). The samples were analyzed with a linear gradient of $20-80 \%$ acetonitrile in $0.1 \mathrm{M} \mathrm{FA}$ in $20 \mathrm{~min}$, flow rate $1.0 \mathrm{~mL} / \mathrm{min}$ at temperature $22{ }^{\circ} \mathrm{C}$. The fractions collected at $12 \pm 0.5 \mathrm{~min}$ were evaporated to dryness and transferred to appropriate small glass tubes with $100 \%$ methanol. The methanol was then evaporated in $\mathrm{N}_{2}$ stream. Next the residue was methylated with diazomethane dissolved in diethyl ether. After this, the diethyl ether was evaporated with $\mathrm{N}_{2}$, and the residue was dissolved in $30 \mu \mathrm{L}$ of $100 \%$ methanol. $1 \mu \mathrm{L}$ of this sample was analyzed by gas chromatography (GC)/mass spectrometry (MS) (Auto-System XL coupled to a TurboMass, Perking-Elmer) using an MDN-5 column ( $30 \mathrm{~m} \times 0.25 \mathrm{~mm}, 0.25 \mu \mathrm{m}$ phase thickness; Supelco). The GC temperature program was set at $60^{\circ} \mathrm{C}$ for $1 \mathrm{~min}, 60-250{ }^{\circ} \mathrm{C}$ at $10^{\circ} \mathrm{C} / \mathrm{min}(5 \mathrm{~min}$ hold), flow rate $1.5 \mathrm{~mL} / \mathrm{min}$, injection port was $280^{\circ} \mathrm{C}$, electron potential $70 \mathrm{eV}$. GC/MS-SIM was performed by monitoring m/z 190 for endogenous ABA, 194 for $\left[{ }^{2} \mathrm{H} 6\right] \mathrm{ABA}, 130$ for endogenous IAA and 132 for $\left[{ }^{2} \mathrm{H} 2\right] \mathrm{IAA}$ and 152 for endogenous SA and 156 for $\left[{ }^{2} \mathrm{H} 4\right] \mathrm{SA}$ according to the method described by Vine et al. [42].

\subsection{Determination of Soluble Sugar Content}

Sugar contents (i.e., glucose, fructose, sucrose, and total sugar concentration) in dried leaf, shoot and fruit samples of the Kırmızı variety were determined according to the extraction method developed by Miron and Scahffer [43] using HPLC (HP 1100 Series), RID (Refractive Index Detector) detector and Transgenomic CARBOSep COREGEL 87C $(250 \times 4.6 \mathrm{~mm}, 5 \mu)$ column in 3 repetitions. Distilled water was used as mobile phase and HPLC conditions were $1.0 \mathrm{~mL} / \mathrm{min}$ flow and $85^{\circ} \mathrm{C}$ oven temperature. Sugar contents in the samples were determined qualitatively and quantitatively using a refractive index detector according to the calibration curves created using the external standard and the retention time of the standard.

\subsection{Nitrogen Analysis}

Nitrogen in leaf samples was determined by the Kjeldahl method, which is a wet burning method recommended by Jacobs [44]. Dried and homogenized samples were weighed $200 \mathrm{mg}$ for each repetition and 1 Kjeldahl tablet and $12 \mathrm{~mL}$ of sulfuric acid were added to nitrogen combustion tubes and put into the incinerator. Samples were burned for a total of $1 \mathrm{~h}$ : $10 \mathrm{~min}$ at $30^{\circ} \mathrm{C}, 10 \mathrm{~min}$ at $60^{\circ} \mathrm{C}$ and $40 \mathrm{~min}$ at $100{ }^{\circ} \mathrm{C}$. The glass tube that completes the burning process was placed in the distillation device and the distillation process was started by placing $25 \mathrm{~mL}$ of boric acid in the flask into the other compartment. $0.1 \mathrm{~N} \mathrm{HCl}$ was added dropwise to the sample, which took the color of onion peel after distillation, and titrated until it turned into the color of boric acid before the reaction.

\subsection{Phosphorus Analysis}

The phosphorus content was determined by the method proposed by Barton [45]. $200 \mathrm{mg}$ of dried and homogenized samples were taken and burned in as furnace at $550{ }^{\circ} \mathrm{C}$ for $8 \mathrm{~h}$. The ash produced after burning was dissolved in $1 / 3 \mathrm{HCl}$ and filtered in blue band. The mixture prepared with $0.5 \mu \mathrm{L}$ Bartone' solution and $4 \mathrm{~mL}$ of distilled water was vortexed. Vortexed samples were placed on plate and absorbance were measured in a spectrophotometer at a wavelength of $430 \mathrm{~nm}$. $50 \mathrm{ppm}$ of phosphorus were used for standard preparation with following concentrations $0 \%, 8.33 \%, 16.6 \%, 33.3 \%, 50 \%, 66.6 \%$, $83.3 \%, 100 \%$. 


\subsection{Macro and Micronutrient Analysis}

$200 \mathrm{mg}$ of dried and homogenized samples were taken and burned in an ash furnace at $550{ }^{\circ} \mathrm{C}$ for $8 \mathrm{~h}$. The ash produced after the combustion was dissolved in $1 / 3 \mathrm{HCl}$ and filtered in the blue band and the $\mathrm{K}, \mathrm{Ca}, \mathrm{Mg}, \mathrm{Fe}, \mathrm{Zn}, \mathrm{Mn}$, and $\mathrm{Cu}$ concentrations were determined in the Varian brand Atomic Absorption Spectrometer [46].

\subsection{Statistical Analysis}

Three biological replicates per experimental variant were performed for each analysis. The normality of the distribution of the 16 observed traits was tested with Shapiro-Wilk's normality test [47] to check whether the analysis of variance (ANOVA) met the assumption that the ANOVA model residuals followed a normal distribution. The homogeneity of variance was tested using Bartlett's test. Multivariate normality and homogeneity of variance-covariance matrices were tested by Box's $\mathrm{M}$ test. A two-way (part, flower) multivariate analysis of variance (MANOVA) was made. Following this, two-way analyses of variance (ANOVA) were performed in order to verify the null hypotheses of a lack of part and flower effects as well as part $\times$ flower interaction effect in terms of the values of the 16 observed traits, independently for each trait. The arithmetic means and standard deviations were calculated. Moreover, Fisher's least significant differences (LSDs) were estimated at a significance level of $\alpha=0.05$. The relationships between the observed traits were estimated using Pearson's correlation coefficients. The GenStat v. 18 statistical software package was used for all the analyses.

\section{Results}

3.1. Effect of Flower Cluster Thinning Application on the Concentration of Semiquinone Radicals and $\mathrm{Mn}^{2+}$ in Organs of Pistachio Trees

In the first two sampling dates (i.e., 3rd May and 1st June), EPR analyses showed significant increased generation of semiquinone radicals in fruits and leaves of pistachio trees, where the flower cluster thinning application was made in relation to the control (i.e., without any flower cluster thinning application) (Figure 3a). In turn, at the third period (26th June), a significant decrease in the concentration of semiquinone radicals is visible in fruits and shoots, especially in trees receiving the flower cluster thinning application. Moreover, the same trend was recorded in fruits and shoots in the recent period of collection of plant material from trees with the flower cluster thinning. Besides, the highest level of radicals was observed in the shoots of pistachio trees without any flower cluster thinning application.

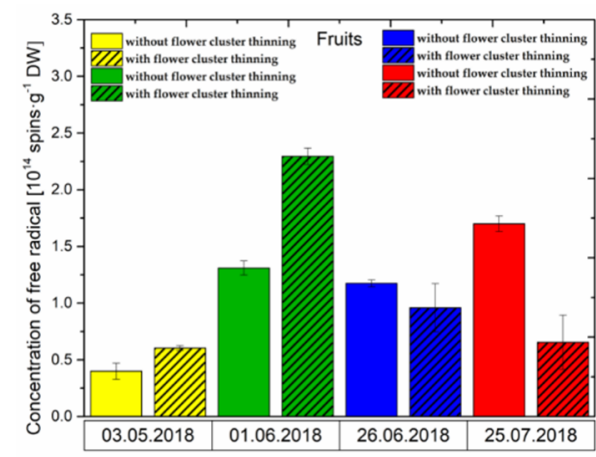

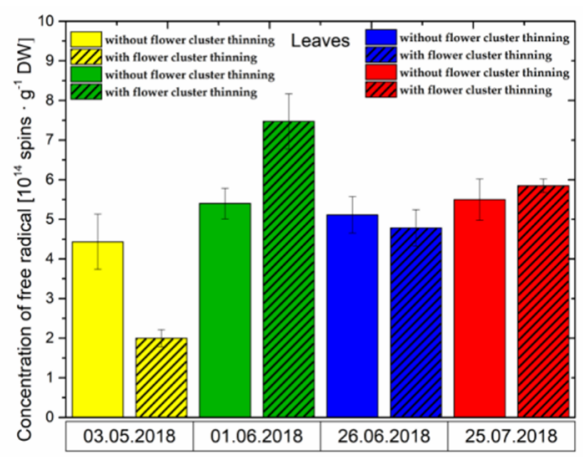

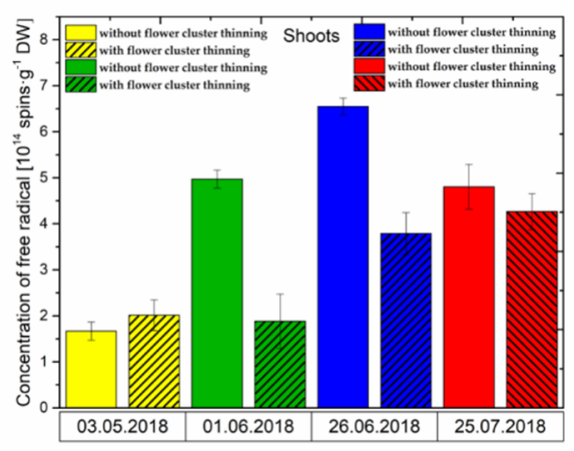

(a)

Figure 3. Cont. 


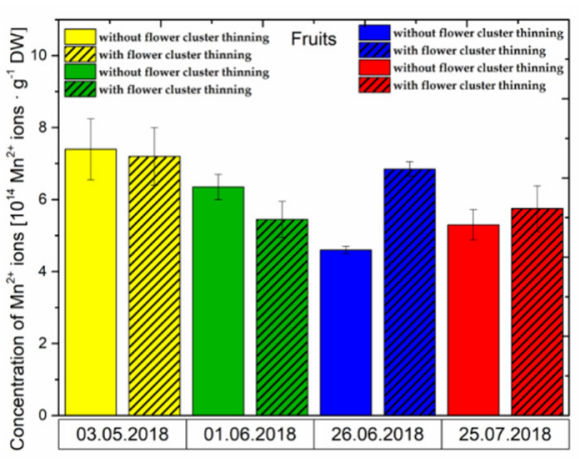

Figure 3. Concentration of Semiquinone Radicals
Without Flower Cluster Thinning Application.
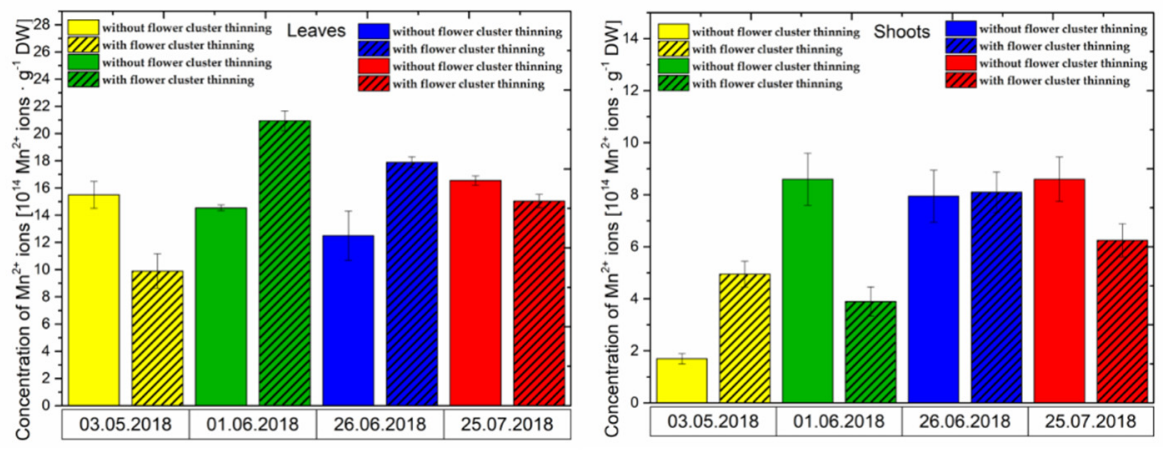

(b)

In turn, the concentration of $\mathrm{Mn}^{2+}$ showed fluctuations. The flower cluster thinning application caused decrease in the level of $\mathrm{Mn}^{2+}$ in leaves of pistachio trees in the first term (3 May), while an increase of these radicals occurred in shoots of pistachio trees with the flower cluster thinning as compared to the control (Figure 3b). At the third period (26 June), increases in concentrations of $\mathrm{Mn}^{2+}$ were recorded in fruits and leaves. The highest level of these ions $\left(21 \times 10^{14} \mathrm{Mn}^{2+} \mathrm{g}^{-1} \mathrm{DW}\right)$ was found in leaves of pistachio because of the flower cluster thinning application.

3.2. Changes in the Concentration of Phytohormones after Flower Cluster Thinning Application in Pistachio Organs

\subsubsection{IAA Content}

At the first stage (in May), the IAA content in fruits of pistachio trees where the flower cluster thinning application was made, was 4-fold higher than in the control. A similar general tendency was noted in leaves and shoots at certain time points. The highest level of IAA was recorded in the shoots and fruits of pistachio in the control (Figure 4). In turn, fruits of pistachio trees at the third time point (where the flower cluster thinning application was done) displayed 3-fold lower concentrations of IAA than the control trees.
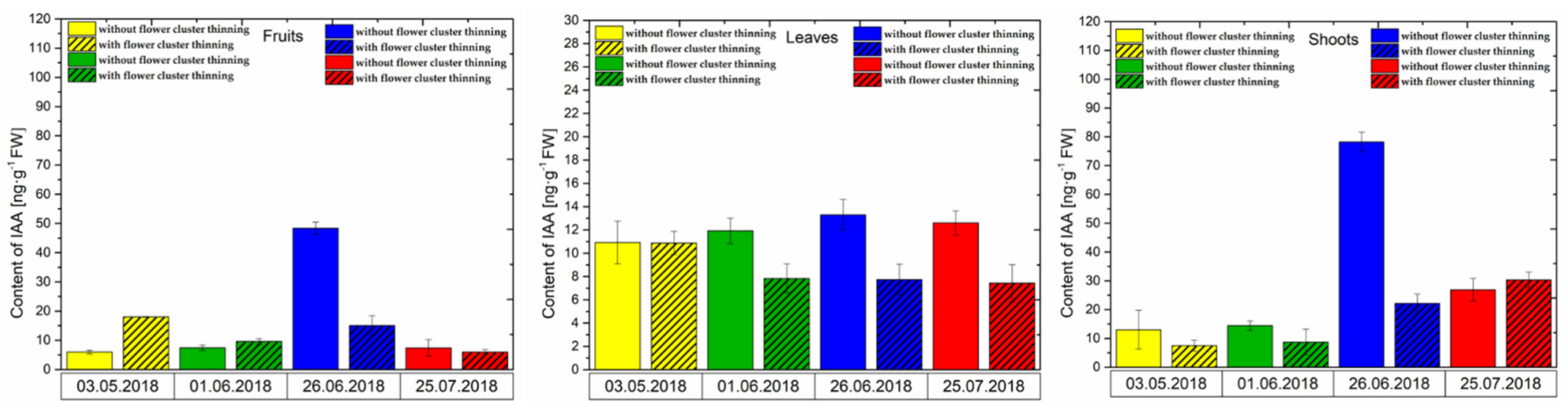

Figure 4. Concentration of IAA in Organs of Pistachio Trees With or Without Flower Cluster Thinning Application.

\subsubsection{ABA Content}

After the flower cluster thinning application, the highest level of ABA was found in pistachio fruits ( $575 \mathrm{ng} \mathrm{ABA} \cdot \mathrm{g}^{-1} \mathrm{DW}$ ) at the first stage (in May) when nuts were collected (Figure 5). Also, a high ABA content was noted in pistachio shoots in the last period of collecting samples, i.e., in July. Attention should also be drawn to the lower ABA level in fruits of pistachio trees from 1st June and leaves from 3rd May, where the flower cluster thinning application to pistachio trees was made. 

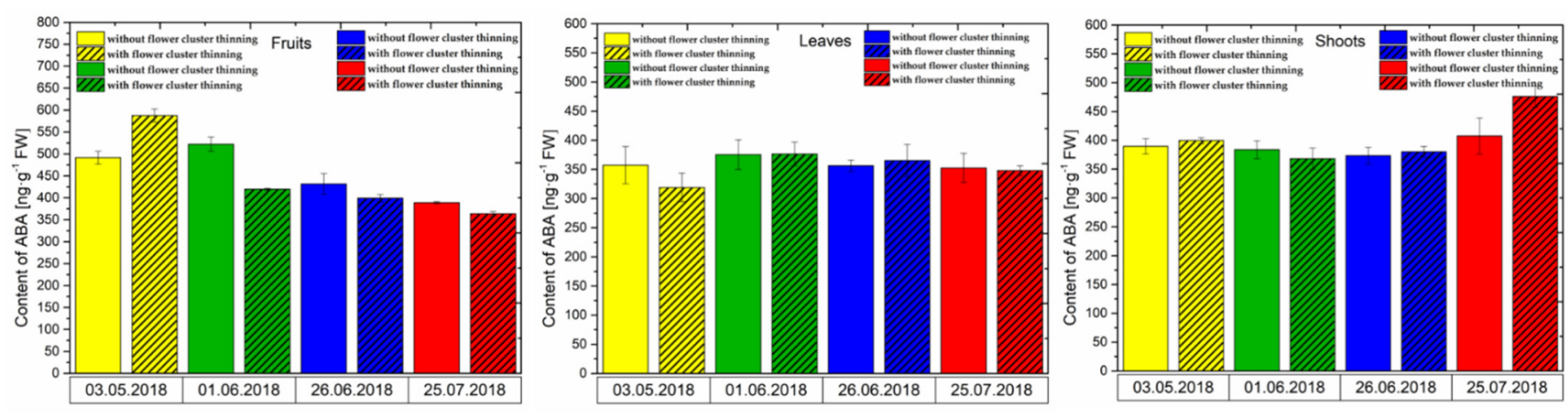

Figure 5. Concentration of ABA in Organs of Pistachio Trees With or Without Flower Cluster Thinning Application.

\subsubsection{SA Content}

It should be emphasized that after the flower cluster thinning application, the level of SA in pistachio organs (fruits, leaves and shoots) was lower than in the control at certain time points (Figure 6). For example, in June, a significant reduction in the SA concentration was noted in the fruits of pistachio trees before applying the flower cluster thinning as compared to the control. In turn, a significant reduction in the SA level was also observed in leaves especially in samples from the first, third and fourth time of plant material collection. Besides, the highest level of SA was recorded in fruits.
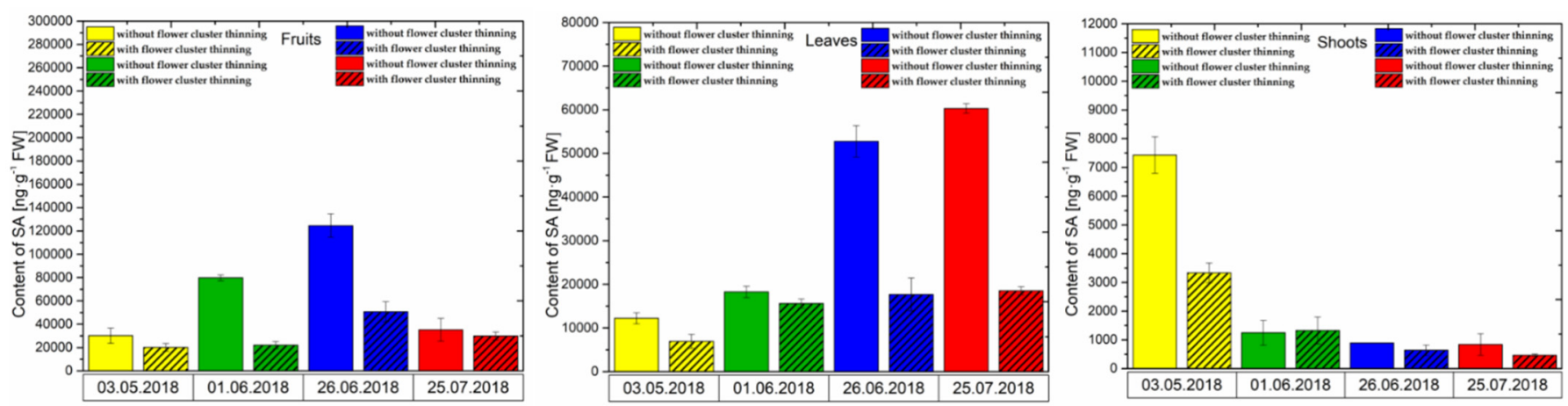

Figure 6. Concentration of SA in Organs of Pistachio Trees With or Without Flower Cluster Thinning Application.

\subsection{Changes in Sugar Levels after the Flower Cluster Thinning Application in Pistachio Organs}

The total sugar content in pistachio organs after the flower cluster thinning application was generally higher than in the control (Figure 7). The significantly higher level of total sugars in the fruits of the pistachio trees following flower cluster thinning than in the control at the first time of nut harvest should draw attention (Figure 7a). A similar tendency at the next time point (on 1st June) in fruits was observed. Statistical analysis showed highly significant differences in these results (Table S1). Besides, at the last sampling time, the total sugar concentration was about 1.8 fold higher in shoots of the pistachio trees with flower cluster thinning than in the control. It should be emphasized that an extremely high fructose content in the nuts of pistachio trees after flower cluster thinning application was observed (2.7-fold higher than in the control) (Figure 7c). Moreover, sucrose concentration in fruits of pistachio trees following flower cluster thinning application that were collected in May, was also 1.2-fold higher than in the control (Figure 7d). 

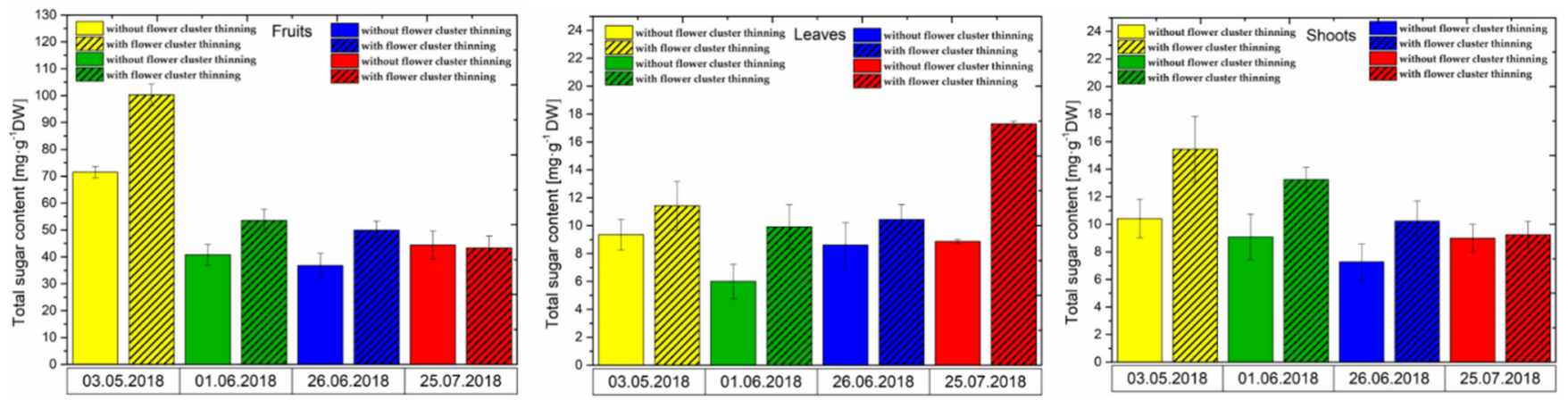

(a)
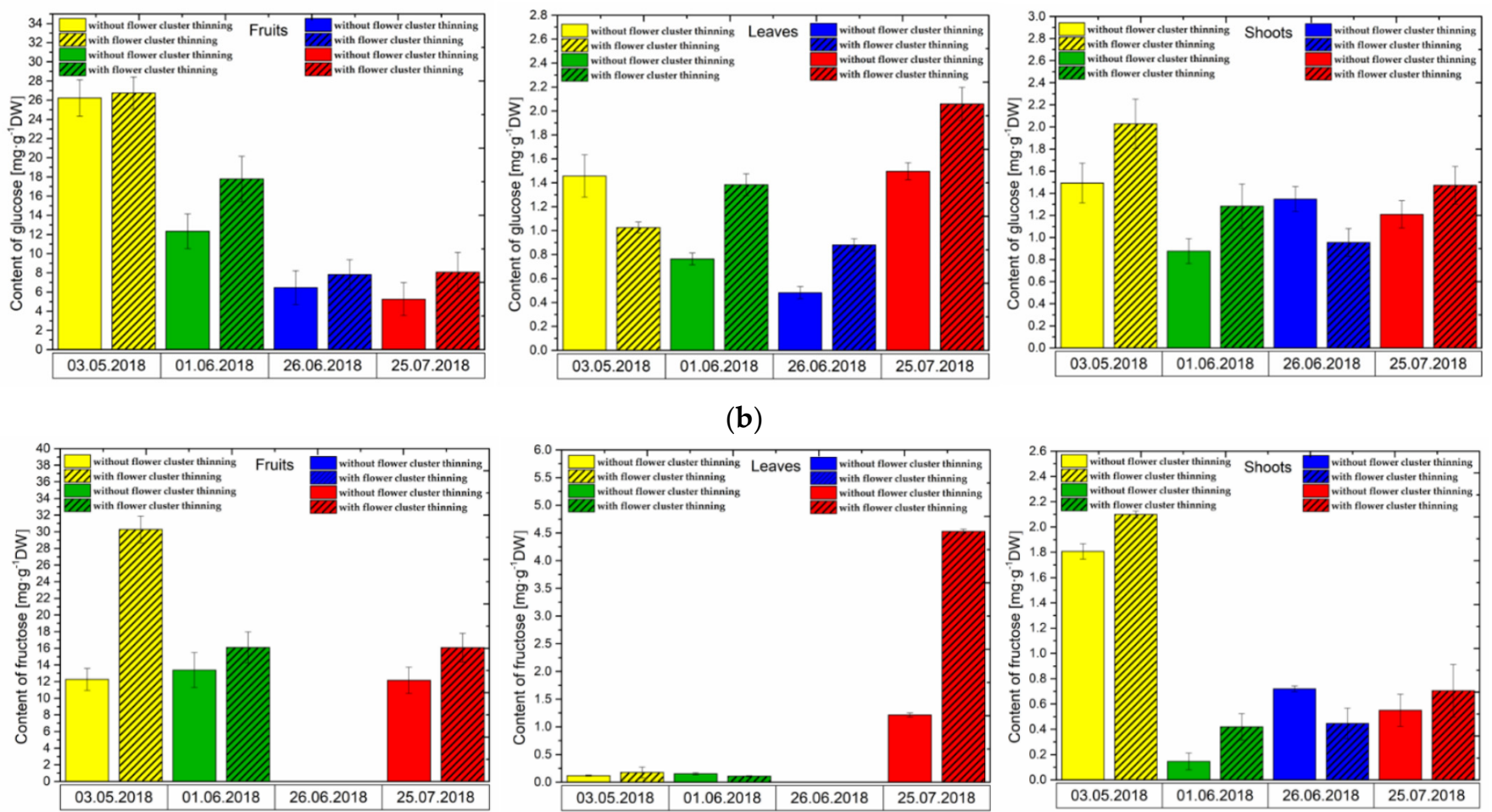

(b)
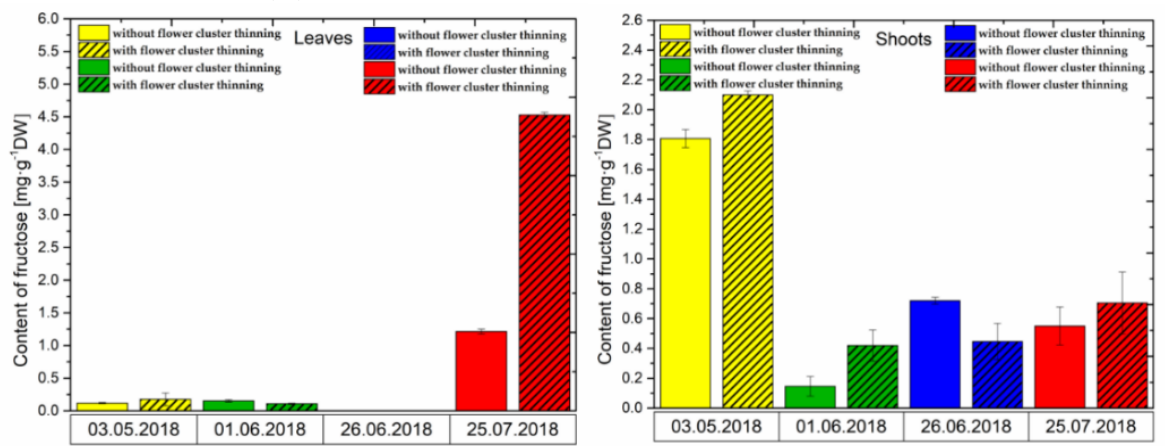

(c)
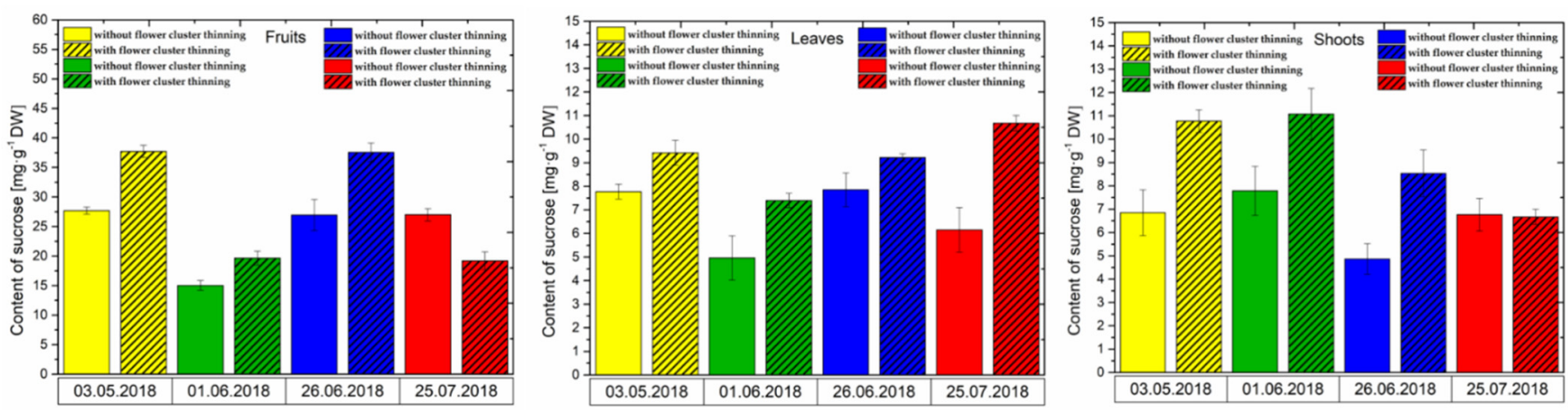

(d)

Figure 7. Cont. 

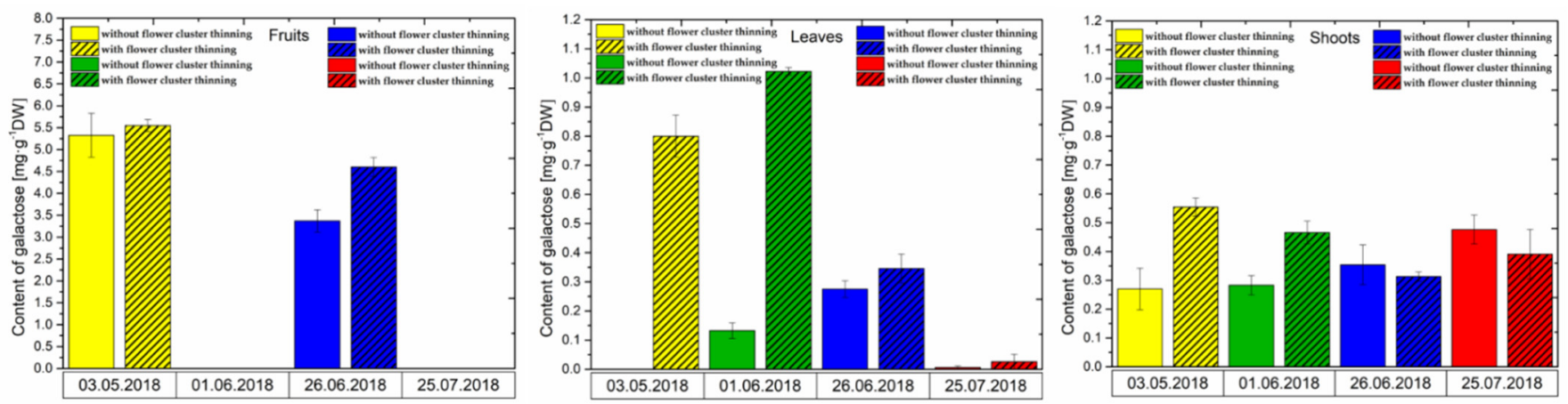

(e)

Figure 7. Total Sugar Content (a), Glucose (b), Fructose (c), Sucrose (d), Galactose (e) in Organs of Pistachio Trees With or Without Flower Cluster Thinning Application.

\subsection{Effect of Flower Cluster Thinning Application on the Concentration of Mineral Elements in Pistachio Organs}

The $\mathrm{Cu}$ content in fruits was higher after flower cluster thinning application as compared to the control (i.e., without cluster thinning) (Figure 8). In leaves, the $\mathrm{Cu}$ content was higher at the second and third period in the pistachio trees after flower cluster thinning and then decreasing for the last sampling point (Figure 8a). In shoots, the content of $\mathrm{Cu}$ was higher on the second harvest point in plants after the flower cluster thinning, while it was lower for the third and fourth harvest dates compared to the appropriate controls. Moreover, the $\mathrm{Mg}$ content in fruits was always lower after the flower cluster thinning application in relation to the control (Figure $8 \mathrm{~b}$ ). Also, in leaves of the above pistachio trees, the content of the $\mathrm{Mg}$ was lower at the first and second harvest dates. A similar tendency was noted in shoots at the last time point. It shoud be stressed that the flower cluster thinning leads to a strong accumulation of the $\mathrm{Mn}$ in fruits of pistachio trees at the last stage (in July); the concentration of the Mn was 13 times higher in these fruits than in the control (Figure 8c). In leaves and shoots of pistachio trees with flower abscission, the Mn concentration was generally lower than in the control. In fruits, the $\mathrm{N}$ content was lower at the first time point in pistachio trees after the flower cluster thinning, while it was higher at all other time points in the treated trees compared to the untreated ones (Figure 8d). In leaves, the content of $\mathrm{N}$ was generally higher at the first, third and fourth dates in treated trees in relation to the appropriate controls. As for the shoot content, it was noticeable that the $\mathrm{N}$ level was lower on the second harvest date in plants after the flower cluster thinning, while it was higher at the last time points in treated trees. Analyzes of the $\mathrm{P}$ content in organs of pistachio trees with flower cluster thinning revealed its levels in fruits were higher in relation to the control, except the last time point (Figure 8e). In leaves and shoots, the P level was also higher on the first and second harvest dates in the treated pistachio trees in relation to the appropriate controls. Additionally, higher levels of this element in leaves and shoots were also observed in 25th July and June 26th, respectively. Moreover, in the fruits of pistachio trees as a result of flower cluster thinning higher the Fe contents were found (Figure 8f). Statistical analysis showed highly significant differences in these results (Table S1).

\subsection{Correlation Coefficients between Observed Traits in Relation to Pistachio Organs}

All the observed traits had normal distribution. The results of the MANOVA test indicated that all the organs (Wilk's $\lambda=0.0056 ; \mathrm{F}=39.37 ; p<0.0001$ ), flower (Wilk's $\lambda=0.5460 ; \mathrm{F}=2.65 ; p=0.004$ ) and organ $\times$ flower interaction (Wilk's $\lambda=0.3595 ; \mathrm{F}=2.13$; $p=0.002$ ) were significantly different regarding all the 16 quantitative traits. ANOVA indicated that the main effects of organs were significant for all the studied traits (Table S1). The main effects of flower were significant for SA, total sugar content, sucrose, $\mathrm{Mn}$, and $\mathrm{P}$ (Table S1). The effects of organ $\times$ flower interaction were statistically significant for $\mathrm{Cu}, \mathrm{Mn}$, 
$\mathrm{N}$ and Fe (Tables S1 and S2). Statistically significant (at 0.05 level) correlation coefficients were observed for 95 from 120 pairs of the observed traits (Table S3, Figure 9).
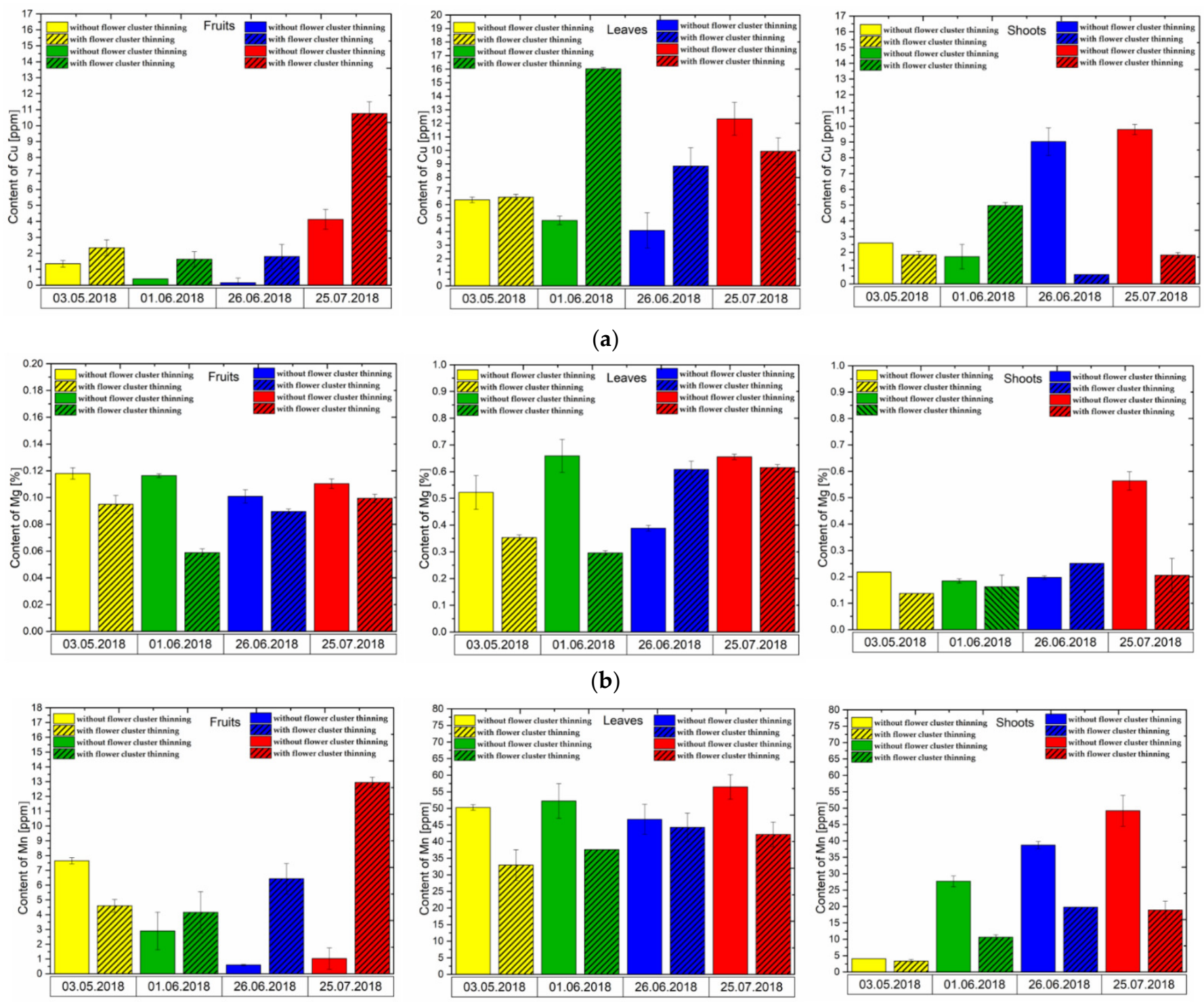

(c)
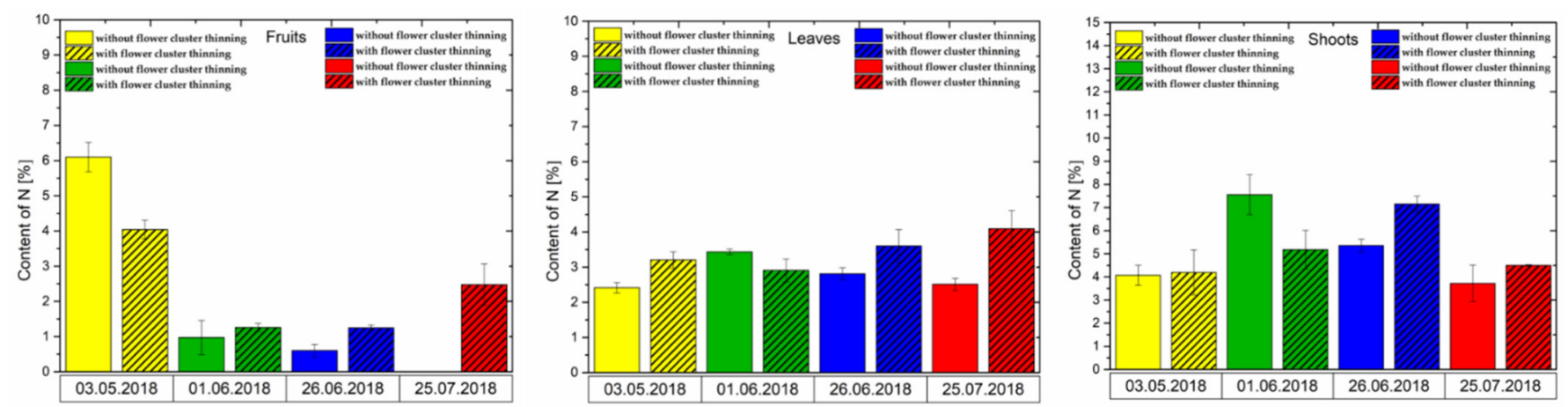

(d)

Figure 8. Cont. 

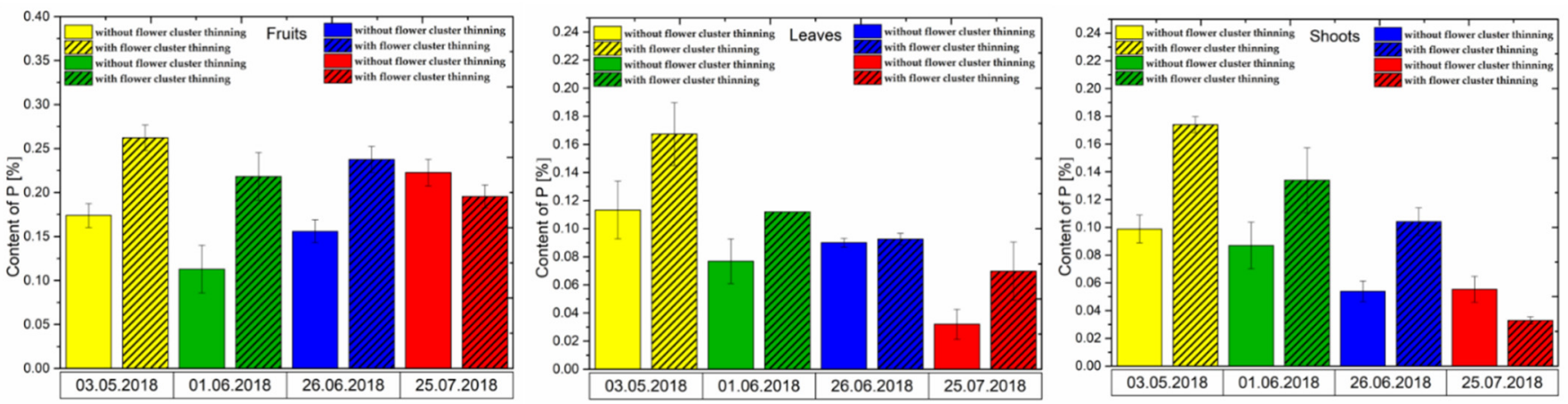

(e)
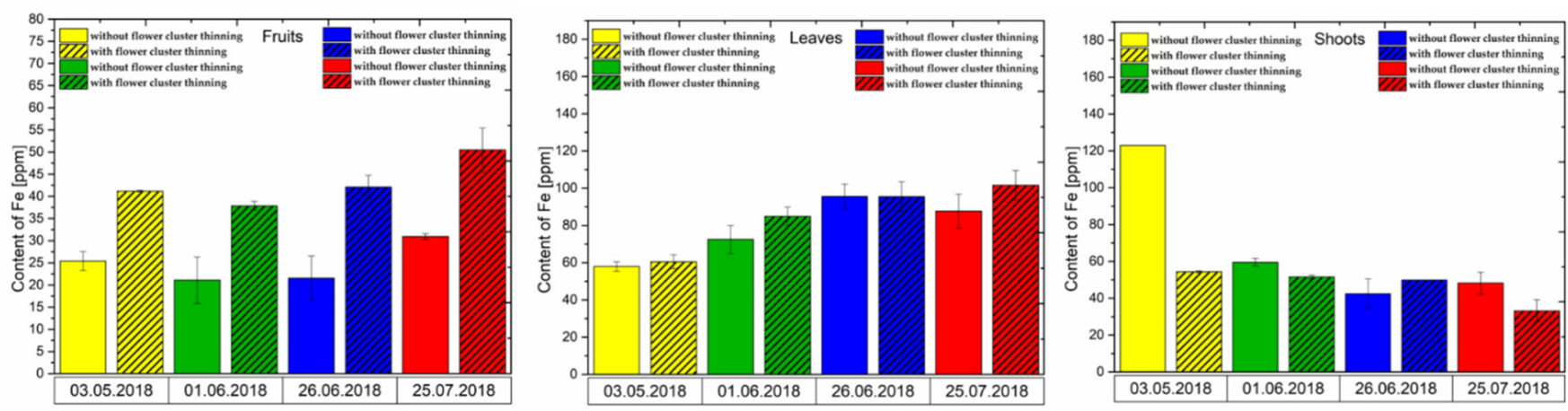

(f)

Figure 8. Cu (a), Mg (b), Mn (c), N (d), P (e) and Fe (f) in Organs of Pistachio Trees With or Without Flower Cluster Thinning Application.
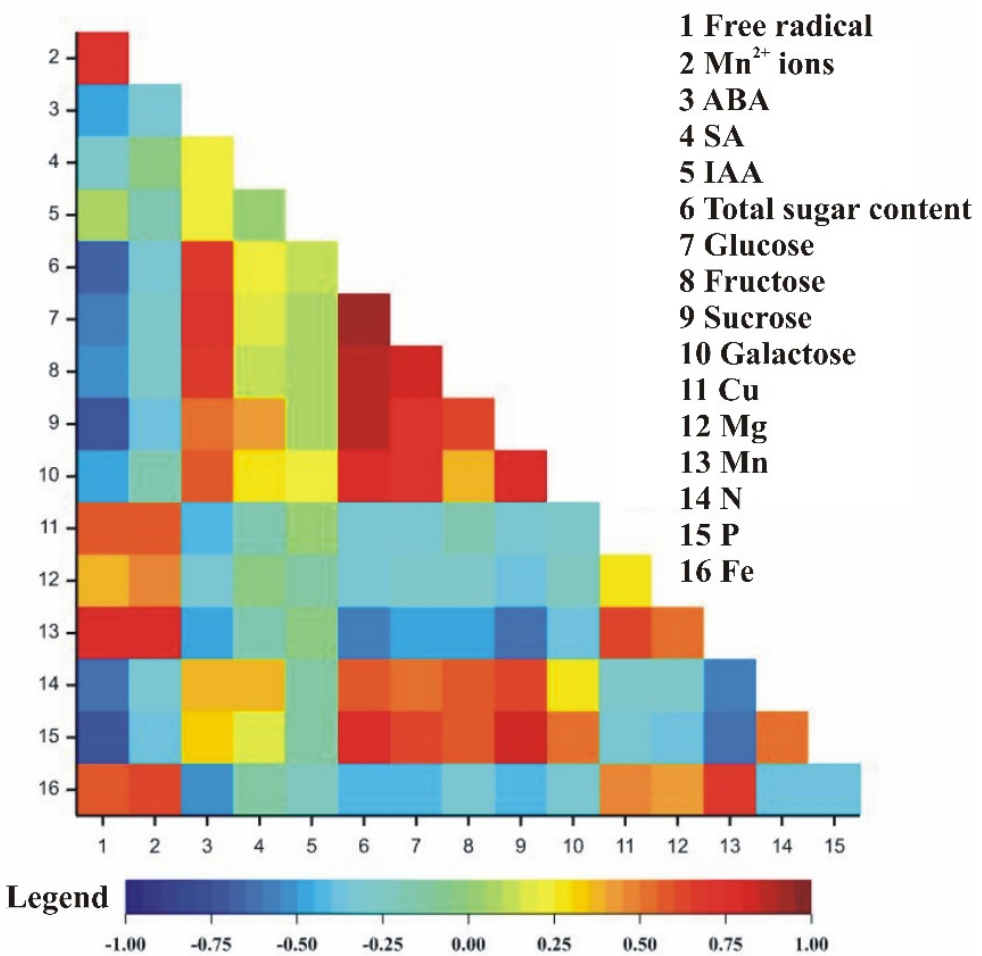

Figure 9. Heatmaps for Pearson's correlation coefficients between the observed traits $\left(r_{0.001}=0.23\right)$. Each cell denotes correlation coefficient between pair of observed traits. The correlation coefficients ranged from -1 (blue) to 1 (red). 


\section{Discussion}

The results of this study show for the first time selected metabolic responses of P. vera L. cv. Kirmizi during different developmental stages. Firstly, within the first two terms collected fruit from pistachio trees with the flower cluster thinning, free radicals accumulation in relation to the control was demonstrated. We analyzed production of these radicals because it was important to know the responses of pistachio trees to hand-thinning of flowers during their development. Our study showed that free radicals gave signals with one g-values of $2.0045 \pm 0.0005$. The g-value of $2.0045 \pm 0.0005$, indicated these radicals are semiquinone-derived radicals [22,48]. Besides, apart from semiquinone radicals, EPR spectroscopy revealed also presence of paramagnetic $\mathrm{Mn}^{2+}$ ions and differences in concentration of these ions in the organs of the pistachio trees with the flower cluster thinning application and the control pistachio trees. EPR spectroscopy is a method for studying materials with unpaired electrons. It is particularly useful for studying metal complexes and organic radicals. We reported here that the concentration of paramagnetic $\mathrm{Mn}^{2+}$ ions demonstrated fluctuations. This result may indicate that $\mathrm{Mn}^{2+}$ ions may change oxidation degree. However, $\mathrm{Mn}^{3+}$ in contrast to $\mathrm{Mn}^{2+}$ ions is extremely difficult to detection by EPR method applied by us ( $9 \mathrm{GHz}$ ). For $\mathrm{Mn}^{3+}$ ions there are observable only forbidden transitions [49]. Besides, statistical analysis showed a strict correlation between observed parameters, i.e., the level of semiquinones and paramagnetic centers $\left(\mathrm{Mn}^{2+}\right)$ detected by EPR spectroscopy, and the concentration of $\mathrm{Cu}, \mathrm{Mg}, \mathrm{Mn}$, and Fe measured by atomic absorption spectrometer. Increase in the level of semiquinone radicals in fruits of pistachio trees may be a consequence of a manual flower cluster thinning. Free radicals are molecular species with unpaired electrons; these radicals are highly reactive and can either extract an electron from molecules or donate an electron to other molecules thus acting as a reductant or an oxidant [50]. The higher levels of semiquinone radicals recorded in pistachio fruit trees may be related to the phenolic compound content and changes in the plant cell redox status as a consequence of manual abscission of the flowers; although phenolics were not analyzed in this study. For example, Yamasaki and Grace [51] using EPR spectroscopy detected phytophenoxyl radicals and have provided evidence for the redox coupling of plant phenolics with ascorbate in the $\mathrm{H}_{2} \mathrm{O}_{2}$-peroxidase system. An important implication of the results described by the above authors is that metal ions may influence the nature of plant phenolics in vivo by altering the lifetime of phenoxyl radicals as the oxidized products. The results in this study clearly indicate that zinc was a spin stabilization agent. Additionally, the above EPR studies revealed that ascorbate can act as a secondary reductant in the CGA peroxidase reaction, but not as a primary electron donor to the peroxidase. Additionally, results of our previous study and other researchers have demonstrated the dependency between to the presence of semiquinone radicals and phenolics using various experimental model systems [22,37,52]. It should be noted that research of Tomaino et al. [53] reported the occurrence of a broad spectrum of phenolic compounds in pistachio, e.g., gallic acid, catechin, eriodictyol-7-O-glucoside, naringenin-7-O-neohesperidoside, quercetin-3-O-rutinoside, eriodictyol, genistein-7-O-glucoside, genistein, daidzein, apigenin, epicatechin, quercetin, naringenin, uteolin, kaempferol, cyanidin-3-O-galactoside and cyanidin-3-O-glucoside. It has been shown that semiquinone radical formation is positively associated with markers of oxidation such as protein carbonyl and total peroxides [54]. Earlier research from Pearce et al. [23] suggested that semiquinone radicals intervene as free radical scavengers, quenching free radical chain reactions involved in the biodegradation of lignocelluloses, and thus protecting cell walls from decay. On the other hand, semiquinone radicals were reported to play an important role in the defense mechanism of plants $[24,25,29,55,56]$. It is believed that these stable free radicals may be associated with the deposition of lignin-like polyphenolic materials, where they may perform a key function in restricting pathogen damage and spread [57-59]. Thus, strong reduction of semiquinone radicals recorded by us in the shoots of pistachio trees at the second and third time point may indicate the involvement of these radicals in the lignification process. Additionally, an interesting issue to consider at this point is the participation of ascorbic acid (AsA) as a multifunc- 
tional metabolite with strong reducing properties that allows the neutralization of free radicals, including ROS and the reduction of molecules oxidized by ROS in cooperation with glutathione in the Foyer-Halliwell-Asada cycle. Studies have demonstrated that AsA is important for the growth and development of woody plants [60].

From a physiological point of view, it can be assumed that higher levels of semiquinone radicals in fruits of pistachio trees after flower removal may be also associated with higher metabolism of these fruits. In parallel, high concentrations of soluble sugars were also noted in those fruits being significantly higher than in the controls. This trend was clearly visible at the first and second time points of nut harvest. Therefore, probably larger amounts of sucrose and monosaccharides were redirected to these organs, intensifying their metabolism. The regulatory function of sugars affects all phases of plant life cycle interacting within phytohormones, controlling the processes of growth and development of plants [61,62]. Grossman and DeJong [63] reported that removal of flowers or subsequent thinning of fruit buds leads to even fruiting (increases its regularity) and increases the growth potential of tree fruits. Regulation of fruiting is one of the keys for obtaining fruits with appropriate and desired quality characteristics [64-67]. In the present study, the content of sucrose as well as glucose and fructose in fruits of pistachio trees following flower cluster thinning application, harvested in May and the first date in June were higher than in the control. It should be emphasized that the immense fructose peak is intriguing in fruits of pistachio trees as a result flower cluster thinning especially at the first term of fruits sampling. Fructose may act both as a signaling molecule as well as an oxidant. This high level of fructose may be related to the hydrolysis of sucrose. Thus, our results prove that both fructose as well sucrose play an important role in the early ripening of pistachio fruits. Stein and Granot [68] reported that most of the fructose found in plants, including also wood plants originates in carbon assimilated during photosynthesis. In photosynthesis, $\mathrm{CO}_{2}$ is fixed in the chloroplasts via the Calvin cycle to yield triose phosphates (triose-P). Triose-P may then be exported to the cytosol, where two triose-P molecules are combined to create one molecule of fructose 1,6-biphosphate (F1,6BP). In turn, as reported Dennis and Blakeley [69], F1,6BP can be dephosphorylated to form F6P, which is isomerized to yield glucose 6-phosphate (G6P). Moreover, sucrose is the primary sugar transported from photosynthetic tissues through the phloem to non-photosynthetic tissues (sink tissues), where it serves as a main carbon source for metabolic pathways. In turn, Marra et al. [70] revealed that the deepest decrement of starch concentration after bud-break until bloom was in the trunk of in pistachio (P. vera L.), whereas, starch concentration started increasing after the initial growth flush.

A positive interdependence was found in this study between the fruit saccharide content and ABA concentration. Evidence was also provided here for the involvement of IAA in the fruit development of pistachio trees after flower cluster thinning. Our data have shown extremely high accumulation of IAA in fruits of pistachio trees with flower removal at the first term collection of plant materials. A similar upward trend in IAA content during fruit set was also reported by Lee et al. [71]. These latter authors also observed an increase in the activity of the soluble acid invertase which was accompanied by an increase in endogenous IAA content. Auxin affects any stage of fruit development. As reported by Nitsch [72], in order to produce flowers and fruits, plants have first to be shifted from a vegetative to a reproductive condition and this change is believed to be under hormonal control. It is well known that IAA, ABA and SA are phytohormones involved in the signalling and regulation of many crucial processes in plants, including fruit growth [73]. Endogenous concentrations of IAA are particularly high at fruit set and during initial growth developmental stages ([73] and references cited in this work). Our analyses using GC/MS-SIM revealed that SA levels were generally lower in fruits, leaves and shoots of pistachio trees after flower cluster thinning as compared to the control organs. Earlier research results documented that some physiological events such as flower bud and embryo formation, development, bud abscission, fruit set and growth are regulated via phytohormones [74-76]. Our data confirmed that, mainly, IAA and ABA are involved 
in the development of pistachio fruits, because their levels were much higher than in the control fruits at the first harvest date of these organs.

Moreover, as reported by Zhang [77], thinning a cluster prior to nut growth will result in a higher percentage of filled nuts on the thinned cluster. Therefore, it is suspected that the intrinsic capacity of trees to store carbohydrates initially determines the percentage of filled nuts. Production of blank nuts is strongly affected by alternate bearing. Probably, the sugar status of a tree entering a crop year, sets the limits of the crop load a tree can set up and carry through maturation to splitting. Kazankaya et al. [78] revealed that kernel sugar composition of nut crops changed based on species, variety, genotype, and accession was affected by different ecological conditions. These authors also showed that the main sugar occurring in many pistachio varieties was sucrose, followed by glucose, fructose, and maltose. In turn, in walnut genotypes, the main sugar was glucose followed by sucrose, fructose and maltose. As for hazelnut, sucrose was the main sugar followed by glucose, maltose, and fructose. This observation indicates the key role of sucrose in the ripening process of pistachio fruits. As mentioned above, pistachio trees are a biennial-bearing crop. Trees that produce too much fruits due to limited carbohydrate and nutrient intake, produce small fruits with low firmness [79]. Fruit thinning contributes to an increase in the leaf to fruit ratio, which has a significant impact on increasing fruit weight, extract content as well as increase the sugar to organic acid ratio [80]. However, it should be noted that too strong thinning may lead to intensified vegetative growth, which may significantly weaken the setting of flower buds in the next year [63]. In turn, too late thinning of the fruits may lead to a weakening of fruit growth, for example its small size [81].

In the present study, we also found that among the analyzed mineral elements $(\mathrm{Cu}, \mathrm{P}$, $\mathrm{Mg}, \mathrm{Mn}, \mathrm{N}$ and $\mathrm{Fe}$ ) in pistachio organs, $\mathrm{Cu}, \mathrm{P}$ and Fe contents in fruits of pistachio trees after flower cluster thinning, were always higher than in the control fruits. Accumulation of these elements may indicate that they were redirected from other organs, e.g., leaves and shoots, to the fruits. These mineral elements play a key role in the physiological processes of plants. Mineral nutrition indeed strongly affects plant metabolism and ultimately affects plant growth, fruit development, fruit quality, nutrition, and postharvest storage [82]. Besides, mineral nutrition, such as $\mathrm{N}, \mathrm{P}$, and $\mathrm{Fe}$, not only directly affects fruit quality but also influences the absorption and the content of other nutrient elements. Moreover, these trace elements mediate biochemical reactions by acting as cofactors for many enzymes, as well as acting as centers for stabilizing structures of enzymes and proteins.

Taken together, our results indicate on participation of semiquinone radicals, paramagnetic manganese ions, IAA, ABA, SA, nutrients, and sugars in $P$. vera organs development on the background of the flower cluster thinning which was done before fructification.

\section{Conclusions}

The obtained results for the first time revealed significant increase in generation of semiquinone radicals and fluctuations in paramagnetic metal ions $\left(\mathrm{Mn}^{2+}\right)$ in fruits of pistachio trees (Pistacia vera L. cv. Kirmizi) as a result flower cluster thinning during development. Additionally, our research shows the important role of signalling molecules such as phytohormones IAA and ABA in the fruit development of pistachios, especially in the early stages. As a result of flower abscission, an increase in the levels of IAA and ABA in the fruits at the first term of fruits sampling was observed. In parallel, the significantly higher level of total sugars, including sucrose and its monosaccharides in the fruits of the pistachio trees with flower cluster thinning than in the control at the first time of harvest nut draws attention. Changes in the level of mineral elements in pistachio organs indicated that these trace elements are very essential for cell functions at molecular and metabolic levels and can be transported from organ to organ depending on the demand given pistachio organ. 
Supplementary Materials: The following are available online at https: / www.mdpi.com/article/ 10.3390/agronomy11112115/s1, Table S1: Mean squares from two-way analysis of variance for observed traits of pistachio, Table S2: Mean values and standard deviations of 16 observed traits, Table S3: Correlation coefficients between all pairs of observed traits.

Author Contributions: I.M. created the concept and participation in research design, directed the implementation of molecular and biochemical research, analyzed and interpreted the data, wrote and prepared the manuscript, M.Z.D., a MA student of Erasmus+ program of I.M. and N.E.K. collected plant material and took part in all molecular and biochemical analyses of plant material, A.W. took part in the preparation of samples for analysis of semiquinone radical, manganese ions and phytohormone, preparing all the results for statistical analysis, prepared the figures and the graphical abstract, was involved in compiling the entire manuscript, prepared references, W.B. contribution to the research methodology and measurements of semiquinone radicals and paramagnetic centers $\left(\mathrm{Mn}^{2+}\right)$ concentrations by EPR, calculation of the results from EPR, J.K. contribution to the research methodology and measurements of phytohormones, J.B. contributed to performing statistical analysis and prepared Tables S1-S3, Figure 9 (heatmap for Pearson's correlation coefficients between observed traits), S..H.A. and İ.D.Ü. contributed to measurements of sugars and mineral elements, M.L. made formal analysis, edited the whole manuscript and proofreading this manuscript, Z.Z. wrote the part of Discussion in relation to thinning of flowers on fruit trees, N.E.K. created the concept and designed the studies, directed the implementation of sugar and mineral element studies, S.K. created the concept and designed the studies, managed the collection of plant material from the orchard, P.J. made formal analysis, edited the whole manuscript and proofreading this manuscript. All authors have read and agreed to the published version of the manuscript.

Funding: Research was funded by Department of Biotechnology, Institute of Natural and Applied Sciences, University of Çukurova, Cukurova University Scientific Research Projects: Project\# FYL2019-12280 and Department of Plant Physiology, Faculty of Agronomy and Bioengineering, Poznań University of Life Sciences (subvention for the Faculty of Agronomy, Horticulture and Bioengineering, Poznań University of Life Sciences grant no 506.145.01.00). Publication was also co-financed within the framework of the Polish Ministry of Science and Higher Education's program: "Regional Initiative Excellence" in the years 2019-2022 (No. 005/RID/2018/19)", financing amount 12000000 PLN.

Institutional Review Board Statement: Not applicable.

Informed Consent Statement: Not applicable.

Data Availability Statement: All Data are available at the corresponding author.

Acknowledgments: We acknowledge for support given by Erasmus + Program. This concept was the basis of a research the basis of the master thesis of Mehmet Zafer Dogu. This work was supported by Department of Plant Physiology, Faculty of Agronomy, Horticulture and Bioengineering, Poznań University of Life Sciences, Institute of Molecular Physics, Polish Academy of Sciences in Poznań, Chair of Plant Physiology and Biotechnology, Nicolaus Copernicus University in Torun and Department of Biotechnology, Institute of Natural and Applied Sciences, University of Çukurova.

Conflicts of Interest: The authors declare no conflict of interest. The funders had no role in the design of the study; in the collection, analyses, or interpretation of data; in the writing of the manuscript, or in the decision to publish the results.

\section{References}

1. Al-Saghir, M.G. Evolutionary History of the Genus Pistacia (Anacardiaceae). Int. J. Bot. 2009, 5, 255-257. [CrossRef]

2. Stevens, P.F. Angiosperm Phylogeny Website. Version 14 July 2017. Available online: http://www.mobot.org/MOBOT/research/ APweb / (accessed on 22 July 2021).

3. AL-Saghir, M.G.; Porter, D.M. Random Amplified Polymorphic DNA (RAPD) study of Pistacia species (Anacardiaceae). Asian J. Plant Sci. 2006, 5, 1002-1006. [CrossRef]

4. Zohary, M. A Monographical Study of the Genus Pistacia. Palest. J. Bot. Jerus. Ser. 1952, 5, 187-228.

5. Kafkas, S. SSR Markers in the Genus Pistacia. In Sustainable Crop Production; IntechOpen: Rijeka, Croatia; London, UK, 2019; ISBN 978-1-78985-318-6.

6. Karcı, H.; Paizila, A.; Topçu, H.; İlikçioğlu, E.; Kafkas, S. Transcriptome Sequencing and Development of Novel Genic SSR Markers From Pistacia vera L. Front. Genet. 2020, 11, 1021. [CrossRef]

7. Kafkas, S. Phylogenetic analysis of the genus Pistacia by AFLP markers. Plant Syst. Evol. 2006, 262, 113-124. [CrossRef] 
8. Belhadj, S.; Derridj, A.; Aigouy, T.; Gers, C.; Gauquelin, T.; Mévy, J.-P. Comparative Morphology of Leaf Epidermis in Eight Populations of Atlas Pistachio (Pistacia atlantica Desf., Anacardiaceae). Microsc. Res. Tech. 2007, 70, 837-846. [CrossRef]

9. Behboudian, M.; Walker, R.; Törökfalvy, E. Effects of water stress and salinity on photosynthesis of pistachio. Sci. Hortic. 1986, 29, 251-261. [CrossRef]

10. Kashaninejad, M.; Tabil, L.G. Pistachio (Pistacia vera L.). In Postharvest Biology and Technology of Tropical and Subtropical Fruit; Woodhead Publishing Series in Food Science, Technology and Nutrition: Oxford, UK, 2011; pp. 218-247, ISBN 978-1-84569-735-8.

11. Isam, A.M. Risk Attitude, Risk Perceptions and Risk Management Strategies: An Empirical Analysis of Syrian Wheat-Cotton and Pistachio Farmers. Ph.D. Thesis, Georg-August-University Göttingen, Göttingen, Germany, 2014.

12. Baazeem, A.; Garcia-Cela, E.; Medina, A.; Magan, N. Interacting Abiotic Factors Affect Growth and Aflatoxin B1 Production Profiles of Aspergillus flavus Strains on Pistachio-Based Matrices and Pistachio Nuts. Front. Microbiol. 2021, 11, 3519. [CrossRef] [PubMed]

13. Georgiadou, M.; Dimou, A.; Yanniotis, S. Aflatoxin contamination in pistachio nuts: A farm to storage study. Food Control. 2012, 26, 580-586. [CrossRef]

14. Kaminiaris, M.D.; Leggieri, M.C.; Tsitsigiannis, D.I.; Battilani, P. AFLA-PISTACHIO: Development of a Mechanistic Model to Predict the Aflatoxin Contamination of Pistachio Nuts. Toxins 2020, 12, 445. [CrossRef]

15. Maggs, D.H. Genetic Resources in Pistachio. In Plant Genetic Resources Newsletter; Roma, Italy, 1973.

16. Hormaza, I.; Dollo, L.; Polito, V.S. Determination of relatedness and geographical movements of Pistacia vera (Pistachio; Anacardiaceae) germplasm by RAPD analysis. Econ. Bot. 1994, 48, 349-358. [CrossRef]

17. Hormaza, I.; Plnney, K.; Polito, V.S. Genetic diversity of Pistachio (Pistacia vera, Anacardiaceae) Germplasm based on Randomly Amplified Polymorphic DNA (RAPD) markers. Econ. Bot. 1998, 52, 78-87. [CrossRef]

18. Al-Shareef, M. Comparative Advantages of Pistachio; Ministry of Agriculture and Agrarian Reform National Agricultural Policy Center (NAPC): Damascus, Syria, 2007; pp. 1-42.

19. Gundesli, M.A.; Kafkas, S.; Zarifikhosroshahi, M.; Kafkas, N.E. Role of endogenous polyamines in the alternate bearing phenomenon in pistachio. Turk. J. Agric. For. 2019, 43, 265-274. [CrossRef]

20. Okay, Y.; Kouml, A.İ. Free Endogenous Growth Regulators in Pistachio (Pistacia vera L.). Afr. J. Agric. Res. 2011, 6, 1161-1169.

21. Benny, J.; Marra, F.P.; Giovino, A.; Balan, B.; Caruso, T.; Martinelli, F.; Marchese, A. Transcriptome Analysis of Pistacia vera Inflorescence Buds in Bearing and Non-Bearing Shoots Reveals the Molecular Mechanism Causing Premature Flower Bud Abscission. Genes 2020, 11, 851. [CrossRef]

22. Barbehenn, R.; Poopat, U.; Spencer, B. Semiquinone and ascorbyl radicals in the gut fluids of caterpillars measured with EPR spectrometry. Insect Biochem. Mol. Biol. 2002, 33, 125-130. [CrossRef]

23. Pearce, N.J.; Perkins, W.T.; Westgate, J.A.; Gorton, M.P.; Jackson, S.E.; Neal, C.R.; Chenery, S.P. A Compilation of New and Published Major and Trace Element Data for NIST SRM 610 and NIST SRM 612 Glass Reference Materials. Geostand. Geoanalytical Res. 1997, 21, 115-144. [CrossRef]

24. Mai, V.C.; Bednarski, W.; Borowiak-Sobkowiak, B.; Wilkaniec, B.; Samardakiewicz, S.; Morkunas, I. Oxidative stress in pea seedling leaves in response to Acyrthosiphon pisum infestation. Phytochemistry 2013, 93, 49-62. [CrossRef]

25. Formela, M.; Samardakiewicz, S.; Marczak, Ł.; Nowak, W.; Narożna, D.; Bednarski, W.; Kasprowicz-Maluśki, A.; Morkunas, I. Effects of Endogenous Signals and Fusarium oxysporum on the Mechanism Regulating Genistein Synthesis and Accumulation in Yellow Lupine and Their Impact on Plant Cell Cytoskeleton. Molecules 2014, 19, 13392-13421. [CrossRef]

26. Woźniak, A.; Bednarski, W.; Dancewicz, K.; Gabryś, B.; Borowiak-Sobkowiak, B.; Bocianowski, J.; Samardakiewicz, S.; RucińskaSobkowiak, R.; Morkunas, I. Oxidative stress links response to lead and Acyrthosiphon pisum in Pisum sativum L. J. Plant Physiol. 2019, 240, 152996. [CrossRef]

27. Durak, R.; Bednarski, W.; Formela-Luboińska, M.; Woźniak, A.; Borowiak-Sobkowiak, B.; Durak, T.; Dembczyński, R.; Morkunas, I. Defense responses of Thuja orientalis to infestation of anholocyclic species aphid Cinara tujafilina. J. Plant Physiol. 2018, 232, 160-170. [CrossRef]

28. Morkunas, I.; Gmerek, J. The Possible Involvement of Peroxidase in Defence of Yellow Lupine Embryo Axase Agains Fusarium Oxysporum. J. Plant Physiol. 2007, 164, 185-194. [CrossRef]

29. Morkunas, I.; Bednarski, W. Fusarium oxysporum-induced oxidative stress and antioxidative defenses of yellow lupine embryo axes with different sugar levels. J. Plant Physiol. 2008, 165, 262-277. [CrossRef] [PubMed]

30. Yoon, H.-K.; Kleiber, T.; Zydlik, Z.; Rutkowski, K.; Woźniak, A.; Świerczyński, S.; Bednarski, W.; Kęsy, J.; Marczak, Ł.; Seo, J.-H.; et al. A Comparison of Selected Biochemical and Physical Characteristics and Yielding of Fruits in Apple Cultivars (Malus domestica Borkh.). Agronomy 2020, 10, 458. [CrossRef]

31. Kozlowski, T.T. Carbohydrate sources and sinks in woody plants. Bot. Rev. 1992, 58, 107-222. [CrossRef]

32. Morkunas, I.; Borek, S.; Formela, M.; Ratajczak, L. Plant Responses to Sugar Starvation. In Carbohydrates-Comprehensive Studies on Glycobiology and Glycotechnology; Chang, C.-F., Ed.; InTech: Rijeka, Croatia, 2012; pp. 409-438, ISBN 978-953-51-0864-1.

33. Morkunas, I.; Waplak, S.; Bednarski, W.; Ratajczak, L.; Garnczarska, M. The Effect of Carbohydrate Nutrition on Free Radical Formation in Pea Embryo Axes Cultivated In Vitro. Plant Physiol. Biochem. 2000, 38.

34. Morkunas, I.; Narożna, D.; Nowak, W.; Samardakiewicz, S.; Remlein-Starosta, D. Cross-Talk interactions of sucrose and Fusarium oxysporum in the phenylpropanoid pathway and the accumulation and localization of flavonoids in embryo axes of yellow lupine. J. Plant Physiol. 2011, 168, 424-433. [CrossRef] [PubMed] 
35. Polat, R.; Aydin, C.; Ak, B.E. Some Physical and Mechanical Properties of Pistachio Nut. Bulg. J. Agric. Sci. $2007,13,237$.

36. Food and Agriculture Organization of the United Nations. FAOSTAT Statistical Database. Available online: http://www.fao.org/ faostat/en/\#home (accessed on 22 July 2021).

37. Morkunas, I.; Formela, M.; Floryszak-Wieczorek, J.; Marczak, L.; Narożna, D.; Nowak, W.; Bednarski, W. Cross-Talk interactions of exogenous nitric oxide and sucrose modulates phenylpropanoid metabolism in yellow lupine embryo axes infected with Fusarium oxysporum. Plant Sci. 2013, 211, 102-121. [CrossRef]

38. Bednarski, W.; Ostrowski, A.; Waplak, S. Low temperature short-range ordering caused by $\mathrm{Mn}^{2+}$ doping of $\mathrm{Rb}_{3} \mathrm{H}\left(\mathrm{SO}_{4}\right)_{2}$. J. Phys. Condens. Matter 2010, 22, 225901. [CrossRef]

39. Morkunas, I.; Garnczarska, M.; Bednarski, W.; Ratajczak, W.; Walpak, S. Metabolic and ultrastructural responses of lupine embryo axes to sugar starvation. J. Plant Physiol. 2003, 160, 311-319. [CrossRef]

40. Morkunas, I.; Bednarski, W.; Kozłowska, M. Response of embryo axes of germinating seeds of yellow lupine to Fusarium oxysporum. Plant Physiol. Biochem. 2004, 42, 493-499. [CrossRef] [PubMed]

41. Morkunas, I.; Bednarski, W.; Kopyra, M. Defense strategies of pea embryo axes with different levels of sucrose to Fusarium oxysporum and Ascochyta pisi. Physiol. Mol. Plant Pathol. 2008, 72, 167-178. [CrossRef]

42. Vine, J.H.; Noiton, D.; Plummer, J.A.; Baleriola-Lucas, C.; Mullins, M.G. Simultaneous Quantitation of Indole 3-Acetic Acid and Abscisic Acid in Small Samples of Plant Tissue by Gas Chromatography/Mass Spectrometry/Selected Ion Monitoring. Plant Physiol. 1987, 85, 419-422. [CrossRef]

43. Miron, D.; Schaffer, A.A. Sucrose Phosphate Synthase, Sucrose Synthase, and Invertase Activities in Developing Fruit of Lycopersicon esculentum Mill. and the Sucrose Accumulating Lycopersicon hirsutum Humb. and Bonpl. Plant Physiol. 1991, 95, 623-627. [CrossRef]

44. Jacobs, M.B. Micro-Kjeldahl Method for Biologicals. J. Am. Pharm. Assoc. 1951, 40, 151-153. [CrossRef]

45. Barton, C.J. Photometric Analysis of Phosphate Rock. Anal. Chem. 1948, 20, 1068-1073. [CrossRef]

46. Pratt, P.F.; Chapman, H.D. Gains and losses of mineral elements in an irrigated soil during a 20-year lysimeter investigation. Hilgardia 1961, 30, 445-467. [CrossRef]

47. Shapiro, S.S.; Wilk, M.B. An Analysis of Variance Test for Normality (Complete Samples). Biometrika 1965, 52, 591. [CrossRef]

48. Foster, M.A. Magnetic Resonance in Medicine and Biology, 1st ed.; Pergamon: Oxford, UK, 1984; ISBN 0-08-030770-1.

49. Tao, Y.; Chen, R.; Li, H.; Yuan, J.; Wan, Y.; Jiang, H.; Chen, C.; Si, Y.; Zheng, C.; Yang, B.; et al. Resonance-Activated Spin-Flipping for Efficient Organic Ultralong Room-Temperature Phosphorescence. Adv. Mater. 2018, 30, e1803856. [CrossRef] [PubMed]

50. Engwa, G.A. Free Radicals and the Role of Plant Phytochemicals as Antioxidants Against Oxidative Stress-Related Diseases; IntechOpen: Rijeka, Croatia, 2018; ISBN 978-1-78984-378-1.

51. Yamasaki, H.; Grace, S.C. EPR detection of phytophenoxyl radicals stabilized by zinc ions: Evidence for the redox coupling of plant phenolics with ascorbate in the $\mathrm{H}_{2} \mathrm{O}_{2}$-peroxidase system. FEBS Lett. 1998, 422, 377-380. [CrossRef]

52. Kehrer, J.P. Free Radicals as Mediators of Tissue Injury and Disease. Crit. Rev. Toxicol. 1993, 23, 21-48. [CrossRef]

53. Tomaino, A.; Martorana, M.; Arcoraci, T.; Monteleone, D.; Giovinazzo, C.; Saija, A. Antioxidant activity and phenolic profile of pistachio (Pistacia vera L., variety Bronte) seeds and skins. Biochimie 2010, 92, 1115-1122. [CrossRef]

54. Barbehenn, R.; Cheek, S.; Gasperut, A.; Lister, E.; Maben, R. Phenolic Compounds in Red Oak and Sugar Maple Leaves Have Prooxidant Activities in the Midgut Fluids of Malacosoma disstria and Orgyia leucostigma Caterpillars. J. Chem. Ecol. 2005, 31, 969-988. [CrossRef]

55. Woźniak, A.; Formela, M.; Bilman, P.; Grześkiewicz, K.; Bednarski, W.; Marczak, Ł.; Narożna, D.; Dancewicz, K.; Mai, V.C.; Borowiak-Sobkowiak, B.; et al. The Dynamics of the Defense Strategy of Pea Induced by Exogenous Nitric Oxide in Response to Aphid Infestation. Int. J. Mol. Sci. 2017, 18, 329. [CrossRef]

56. Morkunas, I.; Woźniak, A.; Mai, V.C.; Rucińska-Sobkowiak, R.; Jeandet, P. The Role of Heavy Metals in Plant Response to Biotic Stress. Molecules 2018, 23, 2320. [CrossRef] [PubMed]

57. Hammel, K.; Kalyanaraman, B.; Kirk, T.K. Substrate free radicals are intermediates in ligninase catalysis. Proc. Natl. Acad. Sci. USA 1986, 83, 3708-3712. [CrossRef] [PubMed]

58. Rayner, A.D.M.; Boddy, L. Fungal Decomposition of Wood: Its Biology and Ecology. In Fungal Decomposition of Wood. Its Biology and Ecology; John Wiley \& Sons Ltd.: Hoboken, NJ, USA, 1988.

59. Kalyanaraman, B. Radical intermediates during degradation of lignin-model compounds and environmental pollutants: An electron spin resonance study. Xenobiotica 1995, 25, 667-675. [CrossRef]

60. Bilska, K.; Wojciechowska, N.; Alipour, S.; Kalemba, E.M. Ascorbic Acid-The Little-Known Antioxidant in Woody Plants. Antioxidants 2019, 8, 645. [CrossRef] [PubMed]

61. Wind, J.; Smeekens, S.; Hanson, J. Sucrose: Metabolite and signaling molecule. Phytochemistry 2010, 71, 1610-1614. [CrossRef]

62. Stokes, M.E.; Chattopadhyay, A.; Wilkins, O.; Nambara, E.; Campbell, M.M. Interplay between Sucrose and Folate Modulates Auxin Signaling in Arabidopsis. Plant Physiol. 2013, 162, 1552-1565. [CrossRef]

63. Grossman, Y.L. Maximum Fruit Growth Potential Following Resource Limitation During Peach Growth. Ann. Bot. 1995, 75, 561-567. [CrossRef]

64. Miller, S.S.; Schupp, J.R.; Baugher, T.A.; Wolford, S.D. Performance of Mechanical Thinners for Bloom or Green Fruit Thinning in Peaches. HortScience 2011, 46, 43-51. [CrossRef] 
65. Rajput, V.; Bhatia, S.K. Changes in Fruit Quality Parameters in Japanese Plum CV. Kala Amritsari with Chemical Flower Thinning. J. Pharmacogn. Phytochem. 2017, 6, 2220-2223.

66. Pereira, J.F.M.; Raseira, A. Raleio. In Pessegueiro; DF: Embrapa, Brasília, 2014; pp. 309-327.

67. Giovanaz, M.A.; Fachinello, J.C.; Spagnol, D.; Weber, D.; Carra, B. Gibberellic Acid Reduces Flowering and Time of Manual Thinning in 'Maciel' Peach Trees. Rev. Bras. De Frutic. Jaboticabal 2016, 38, e-692. [CrossRef]

68. Stein, O.; Granot, D. Plant Fructokinases: Evolutionary, Developmental, and Metabolic Aspects in Sink Tissues. Front. Plant Sci. 2018, 9, 339. [CrossRef] [PubMed]

69. Dennis, D.T.; Blakeley, S.D. Carbohydrate metabolism. In Biochemistry and Molecular Biology of Plants; Buchanan, B.B., Gruissem, W., Jones, R.L., Eds.; American Society of Plant Physiologists: Rockville, MD, USA, 2000; pp. 676-728.

70. Marra, F.; Roxas, A.A.; Marino, G.; Caruso, T. Seasonal changes in starch content in pistachio organs as related to crop load. Acta Hortic. 2018, 1229, 171-176. [CrossRef]

71. Lee, T.-H.; Sugiyama, A.; Ofosu-Anim, J.; Takeno, K.; Ohno, H.; Yamaki, S. Activation of sucrose-metabolizing enzymes and stimulation of sucrose uptake by auxin and sucrose in eggplant (Solanum melongena L.). J. Plant Physiol. 1997, 150, 297-301. [CrossRef]

72. Nitsch, J.P. The Role of Plant Hormones in Fruit Development. Ph.D. Thesis, California Institute of Technology, Pasadena, CA, USA, 1951.

73. Pérez-Llorca, M.; Muñoz, P.; Müller, M.; Munné-Bosch, S. Biosynthesis, Metabolism and Function of Auxin, Salicylic Acid and Melatonin in Climacteric and Non-climacteric Fruits. Front. Plant Sci. 2019, 10, 136. [CrossRef]

74. Takeda, F.; Crane, J. Abscisic Acid in Pistachio as Related to Inflorescence Bud Abscission. J. Am. Soc. Hortic. Sci. 1980, 105, 573-576.

75. Marino, F.; Greene, D.W. Involvement of Gibberellins in the Biennial Bearing of Apples Malus Domestica Cultivar Early Mcintosh. J. Am. Soc. Hortic. Sci. 1981, 106, 593-596.

76. Vemmos, S.N. Carbohydrate content of inflorescent buds of defruited and fruiting pistachio (Pistacia vera L) branches in relation to biennial bearing. J. Hortic. Sci. Biotechnol. 1999, 74, 94-100. [CrossRef]

77. Zhang, S.Y.; Chauret, G.; Swift, D.E.; Duchesne, I. Effects of precommercial thinning on tree growth and lumber quality in a jack pine stand in New Brunswick, Canada. Can. J. For. Res. 2006, 36, 945-952. [CrossRef]

78. Kazankaya, A.; Balta, M.F.; Yörük, I.H.; Balta, F.; Battal, P. Analysis of Sugar Composition in Nut Crops. Asian J. Chem. 2008, 20, 1519-1525.

79. Whiting, M.D.; Lang, G.A. 'Bing' Sweet Cherry on the Dwarfing Rootstock 'Gisela 5': Thinning Affects Fruit Quality and Vegetative Growth but Not Net $\mathrm{CO}_{2}$ Exchange. I. Amer. Soc. Hort. Sci. 2004, 129, 407-415. [CrossRef]

80. Usenik, V.; Orazem, P.; Stampar, F. Low leaf to fruit ratio delays fruit maturity of 'Lapins' sweet cherry on Gisela 5. Sci. Hortic. 2010, 126, 33-36. [CrossRef]

81. DeJong, T.; Johnson, R.; Castagnoli, S. Computer simulation of the carbohydrate economy of peach crop growth. Acta Hortic. 1990, 276, 97-104. [CrossRef]

82. Bai, Q.; Shen, Y.; Huang, Y. Advances in Mineral Nutrition Transport and Signal Transduction in Rosaceae Fruit Quality and Postharvest Storage. Front. Plant Sci. 2021, 12, 68. [CrossRef] 